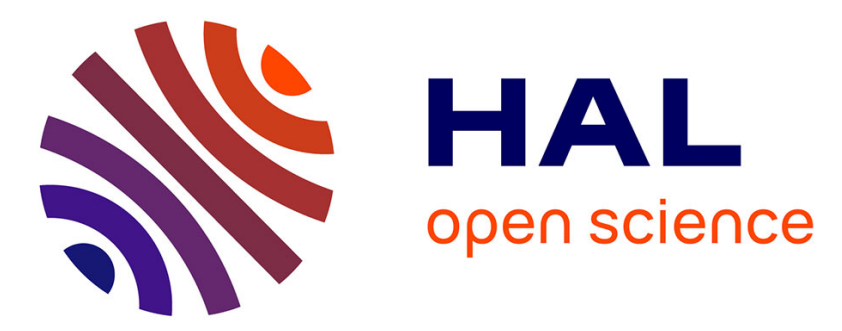

\title{
Une cime pyrénéenne consacrée à Jupiter : Le Mont-Sacon (Hautes-Pyrénées)
}

\author{
Georges Fouet, André Soutou
}

\section{To cite this version:}

Georges Fouet, André Soutou. Une cime pyrénéenne consacrée à Jupiter: Le Mont-Sacon (HautesPyrénées). Gallia - Fouilles et monuments archéologiques en France métropolitaine, 1963, 21 (2), pp.275-294. 10.3406/galia.1963.2392 . hal-01934248

\section{HAL Id: hal-01934248 \\ https://hal.science/hal-01934248}

Submitted on 25 Feb 2020

HAL is a multi-disciplinary open access archive for the deposit and dissemination of scientific research documents, whether they are published or not. The documents may come from teaching and research institutions in France or abroad, or from public or private research centers.
L'archive ouverte pluridisciplinaire HAL, est destinée au dépôt et à la diffusion de documents scientifiques de niveau recherche, publiés ou non, émanant des établissements d'enseignement et de recherche français ou étrangers, des laboratoires publics ou privés.

\section{(1) (1) $\$$}

Distributed under a Creative Commons Attribution - NonCommercial - NoDerivatives| 4.0 
galerie sans doute non couverte et précédéc d'une exèdre semi-circulaire, pourrait être celui d'un mausolée ou d'un pelit lemple. L'absence d'indices empêche actucllement de préférer l'une ou l'autre hypothèse. Ce qui est certain, c'est que cet édifice devait dépendre de la villa voisine et il témoigne de l'importance de celle-ci.

Celle villa est encore mal connue. Des fouilles ultérieures permellront sans doute de l'étudier plus précisément. Les monnaies de la fin de la République el du Ier sic̀cle, trouvées fortuitement, laissent supposer un habital de celte époque. Cette hypothèse demandera d'être vérifiée; car nous touchons à une question intéressant l'histoire de l'organisation des domaines ruraux en Provence et de l'implantation de l'habitat. On connaît bien les cités romaines et certaines stations routières, mais l'on ne sait encore rien sur la manière dont s'esl lransformé le paysage rural avec l'extension de la romanisation.

Abbé R. Boyer et P.-A. FÉvrier.

\section{Une cime pyrénéenne consacrée à Jupiter : Le Mont-Sacon (Htes-Pyrénées).}

Le massif du Mont-Sacon, qui culmine au Pic de Tourroc (1541 mètres), appartient à la zone calcaire exlerne du nord des Pyrénées, zone dite de l'Ariège's symétrique de la zone

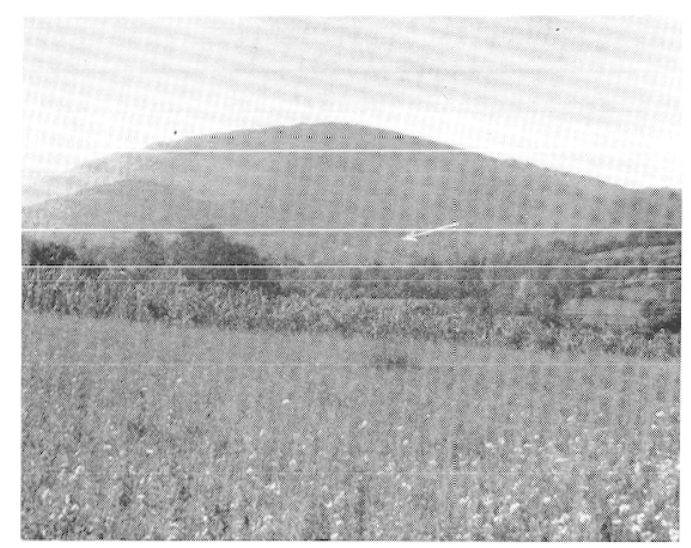

Fig. 1. -.. Le Hont-Sacon dominant Saint-Bertrand-deComminges (fleche). Vue prise de Labroquère (Pholo G. Fouel).

calcaire espagnole par rapport au noyau central granilique. Ce massif se dresse en bordure de la plaine sous-pyrénéenne, entre la vallée de la Barousse et celle de l'Arize, sous-affluent de la Neste, qui débouchent sur la Garonne de part et d'aulre de Saint-Bertrand-de-Comminges. Vue de Saint-Gaudens, sa crête allongéc forme

(1) М. Sонке, I.es Pyrenees, Paris, 1946, p. 17. un dôme aplati qui s'étire en une courbe harmonieuse du sud-est au nord-ouest (fig. 1 et 2).

Le Mont-Sacon domine de sa masse boisée, qu'éclaircissent à peine quelques artigues de pente et le pâturage du sommet, les villages d'Ourde, de Bramevaque et de Sacoué, dont les limites communales se rejoignent au Pic de Tourroc, c'esti-à-dire à l'endroit, même oì les fouilles ont eu lieu. Du haut du sommet on embrasse un paysage immense, depuis la chaîne centrale, au sud-ouest, couronnée de rocs et de névés, jusqu'à la vallée de la Garonne qui s'étend, au nord-est, par-delà le Plantaurel, en direction de Toulouse.

Depuis longtemps une auréole de légendes et de récits fabuleux entoure le Mont-Sacon : "Montagne bien ètrange, en effet, et qui offrirait de fantasmagoriques spectacles si le regard des mortels pouvait plonger dans ses entrailles. Les orifices dont sa carapace est criblée peuvent-ils avoir d'autre objet que de livrer passage à des puissances d'un autre monde? Ils se présentent sous des formes variées : là, ce sont des puits béants dont la profondeur maximum est d'une quarantaine de mètres ; ici leurs ténèbres dessinent sur la roche des niches, des croissants, des lézards ; ailleurs, ce sont des grottes dont l'une a été rendue célèbre par la tragique histoire de l'Abbé d'Agos. Par contre, l'énorme termitière se couronne d'un joli terrain plat auquel la 


\section{Lannemezan}

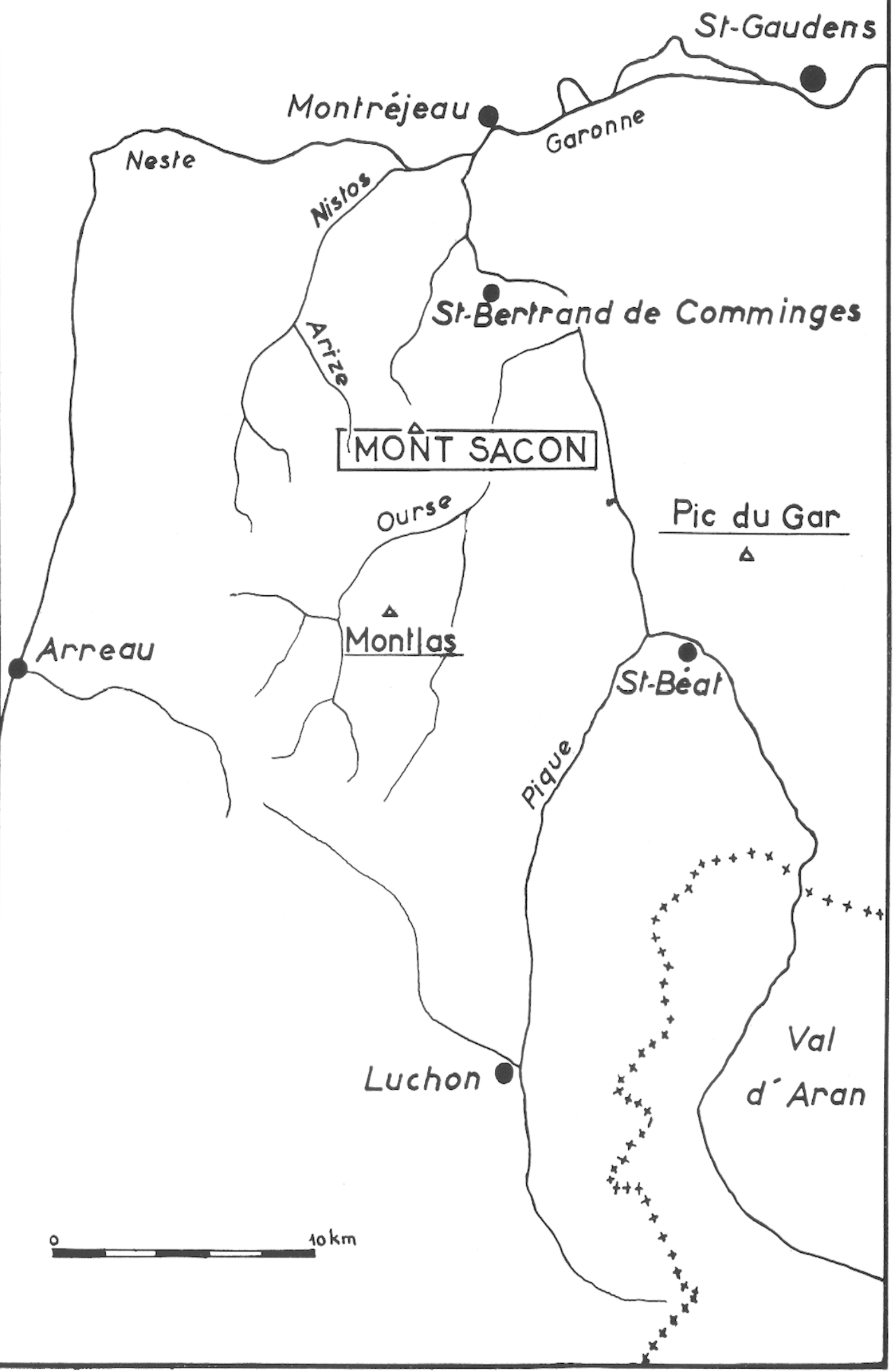

Fig. 2. - Ia région du Mont-Sacon (croquis A. Soulou). 
légende a donné le nom de Jardin de la reine Marguerite. . $)^{2}$

La tradition orale, tant à Nistos ${ }^{3}$ qu'en Barousse ${ }^{4}$ perpétue le terme poétique qu'avail noté M. Pène : des traces, dit-on, seraient restées, des Jardins que la "Reine Marguerile " aurait fait établir sur la cime du Mont-Sacon. L'on y aurait, en particulier, observé des roses...

Comme il est évident que des fleurs aussi délicates n'ont jamais pu vivre sur ce pointement rocheux exposé à toutes les intempéries, il faut croire que la légende est née du fait que les bergers ont distingué sur des autels restés en place des figures en forme de roses, c'est-àdire des rosaces gravées sur le marbre ${ }^{5}$. L'altribution de ces prétendus Jardins à la "Reine Marguerite " fait intervenir une autre légende, celle de la détention supposée de la Comtesse de Comminges durant 23 ans dans le château féodal de Bramevaque ${ }^{6}$.

(2) J. I. Prine, La Barousse, le pays, son histoire, ses mours, s. d., Meaux, p. 33.

(3) M. et Mme Rumeau, instituteurs à Nistos (IItes. Pyr.), avaient recueilli de multiples renseignements archéologiques sur ces pays auxquels ils s'étaient attachés. Nous devons rendre hommage à la mémoire de M. Rumeau, récemment décédé, et prier $M^{\text {me }}$ Rumeau d'agréer l'expression de notre bien vive gratitude pour tous les renseignements aimablement communiqués.

(4) Nous présentons nos plus vifs et amicaux remerciements à M. le Délégué de Barousse à Bramevaque, à M. Sosl, Conseiller Général, et surtout à M. Portopan, Maire de Sacoué, pour toutes indications et aides libéralement prodiguées.

(5) A titre anecdotique et de témoignage sur le processus de création légendaire, voici le récit de notre découverte des marbres à laquelle avaient assisté divers témoins de Sacoué et de Bramevaque, tel qu'il ćtait colporté trois mois plus tard dans la vallée voisine de la Garonne et qu'il fut communiqué par M. le Curé de Fronsac, intrigué, à la Société Julien Sacaze : "M. Norbert Casteret vient de découvrir au fond d'un gouffre situé sur le Mont-Sacon 97 statuettes d'argent. Il a été obligé de louer des ouvriers, qui ployaient sous la charge, pour les redescendre en Barousse...". M. Casteret, explorateur intrépide, auteur de nombreuses découvertes, est devenu légendaire dans le pays. De plus il est exact qu'il a exploré, il y a déjà pas mal d'années, des gouffres dans cette montagne. Les petits autels de marbre blanc ont dù dans un premier récit recevoir qualification de "statuettes blanches." M. Casteret a assuré ne pas être monté de l'année sur le Mont-Sacon.

(6) Ch. Higounet (Le Comté de Comminges, de ses
C'est à M. Raymond Lizop, l'érudit historien du Comminges antique, que revient le mérite d'avoir le premier souligné l'existence probable d'autels votifs sur la cime du Mont-Sacon, où on les aurait vus encore au xvir ${ }^{\mathrm{e}}$ siècle : "Le manuscrit de la. Collection Duchesne, à la Bibliothèque Nationale ${ }^{7}$, écril-il dans son remarquable volume consacré au Comminges el au Couserans avant la domination romaine ${ }^{8}$, contient d'intéressantes notes sur Saint-Bertrand-de-Comminges et la région voisine, peut-être de la main d'Ö̈henart. Ces notes renferment le passage suivant :

Montsacon, au-dessus de Tibiran, qui est une forl haule monlagne où l'on voil diverses marques qu'aucuns prennent pour armoiries.

Il semble, ajoute M. Lizop, qu'il s'agisse là d'autels votifs visibles, encore en place à cette époque sur la montagne du Mont-Sacon et portant, gravés à la pointe sur le marbre comme beaucoup de ceux qui figurent dans les collections, des rosaces, svastikas, rouelles, etc. "

Cependant, malgré la publication d'indices aussi prometteurs, aucune recherche sérieuse ne semble avoir été effectuée par la suite sur le Mont-Sacon. Ce n'est, qu'en octobre 1956 que la Revue de Comminges informait ses lecteurs de la découverte par $M^{\text {me }}$ Rumeau, institutrice à Nistos, d'un autel votif, non pas sur la cime de la montagne, mais 200 mètres plus bas devant l'abri rocheux nommé "Le Four de Pènetoue "sous le pic du même nom ${ }^{9}$. Une lettre $^{10}$, puis la visite que nous fîmes à

origines, à son annexion à la Couronne, thèse, ToulouseParis, 1949) note que cette légende ne saurait être retenue. De Saint-Marcet, "la dame de Comminges" avait été amenée au château de Saint-Julien puis en Béarn (note 70, p. 598).

(7) Catalogue $n^{\circ} 17$, vol. LXVII, fol. 69 , 269, cotes données par M. I.izop.

(8) R. Lizop, Le Comminges et le Couserans avant la domination romaine, Toulouse - Paris, 1931, pp. 232233, note 158. R. Iızop, Les Convenae et les Consoranni (Comminges el Couserans), Toulouse - Paris, 1931, pp. $158-377$.

(9) Bertrand SAPĖse, Chronique Commingeoise : Trouvailles archéologiques en montagne, Revue de Comminges, LXIX, 1956, p. 131-132.

(10) Lettre du $10,10 / 1956$ de $M^{\text {me }}$ Rumeau à M. Fouet : "Sous le porche rocheux... est une pierre triangulaire de nature différente des roches environ- 


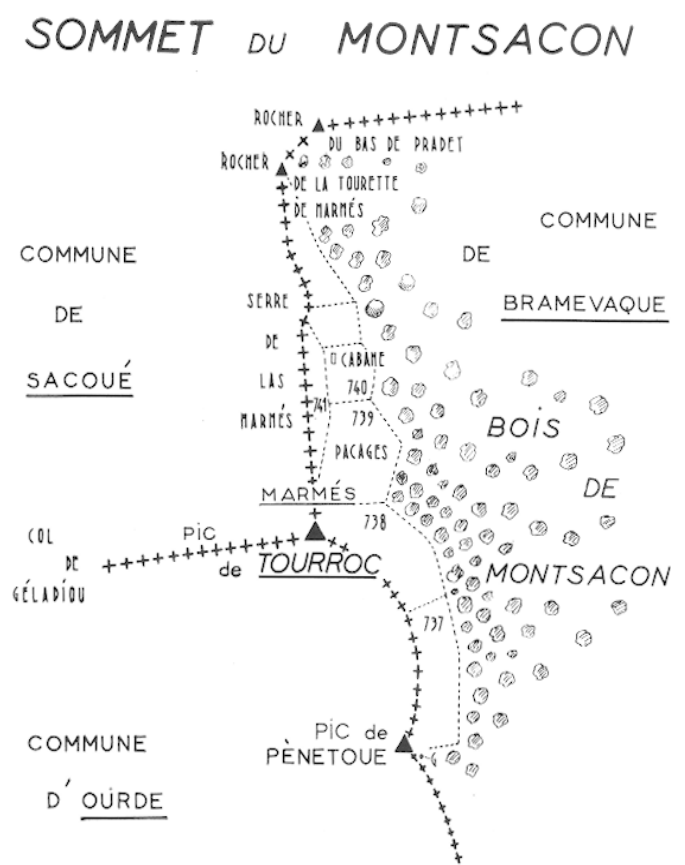

Fig. 3. - Le sommet du Mont-Sacon (croquis G. Fouel).

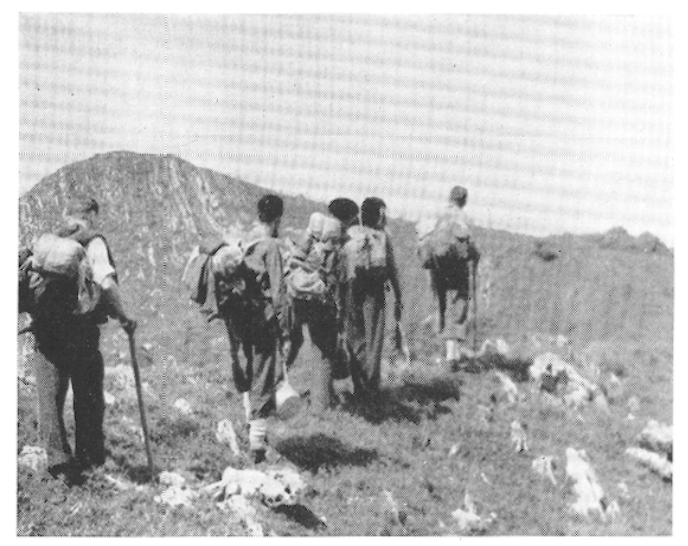

Fig. 5. - Le sommet de Tourroc vu du Pic de Pènetone (Photo J. H. Fourcade).

Mme Rumeau le dimanche 24 octobre suivant, nous apprenaient qu'elle n'avail pas en réalité trouvé un autel votif, mais seulement des rochers pouvant peut-être marquer l'emplacement de quelque lieu consacré, antérieur à l'époque romaine. L'examen que nous fîmes

nantes ; à còté, un tertre où l'on tient bien aisément debout et devant, probablement, un dolmen. Ce n'est pas un autel volif, mais fort probablement le lieu où l'on cólèbr'dil un culte..."

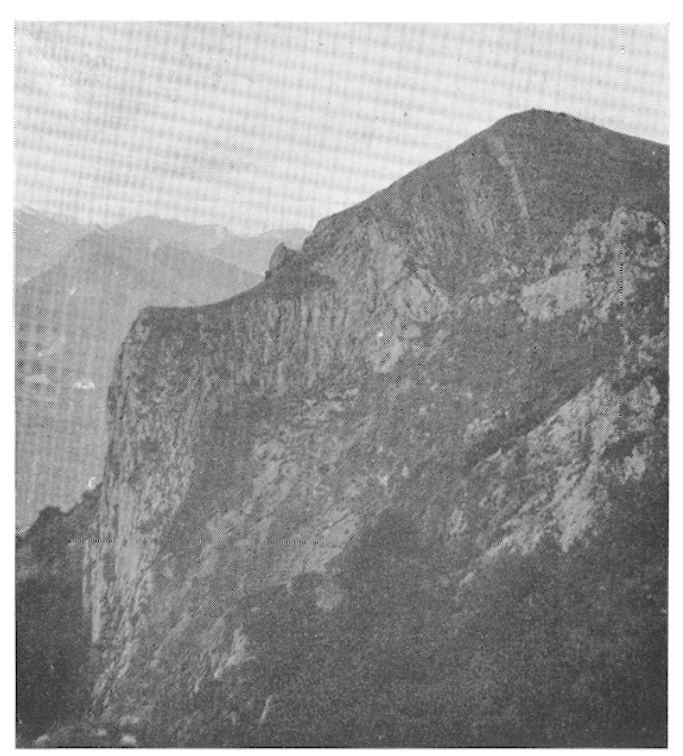

Fig. 4. - Crête du pacage terminal du Mont-Sacon. Au fond le sommel de Tourroc (Pholo (i. Fouet).

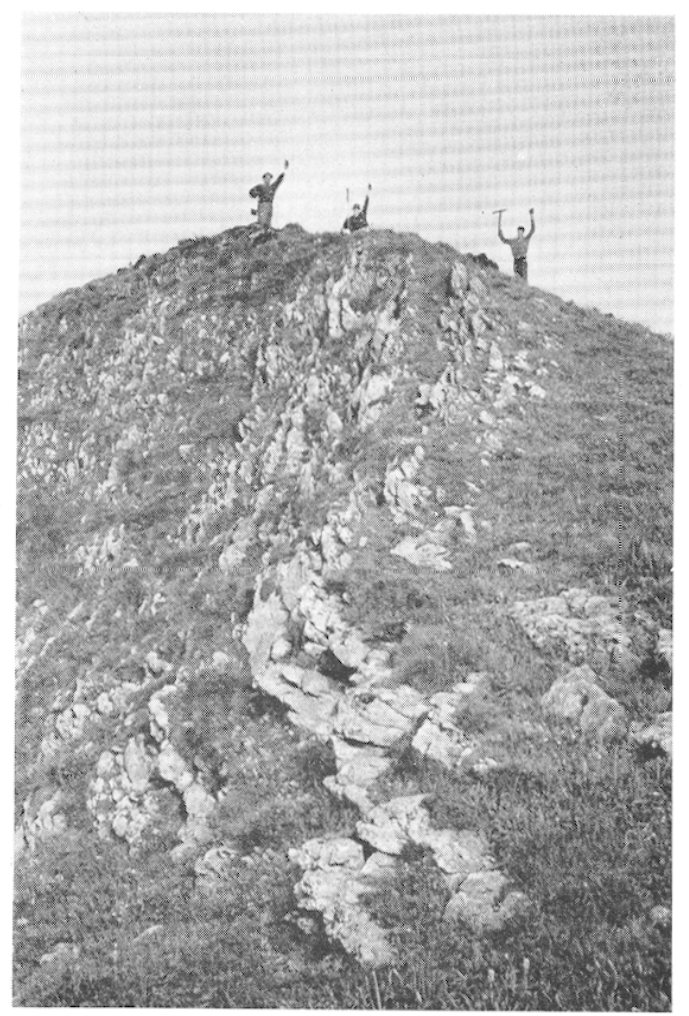

Fig. 6. - - l.e sommel de Tourroc (Photo G. Fonet). 


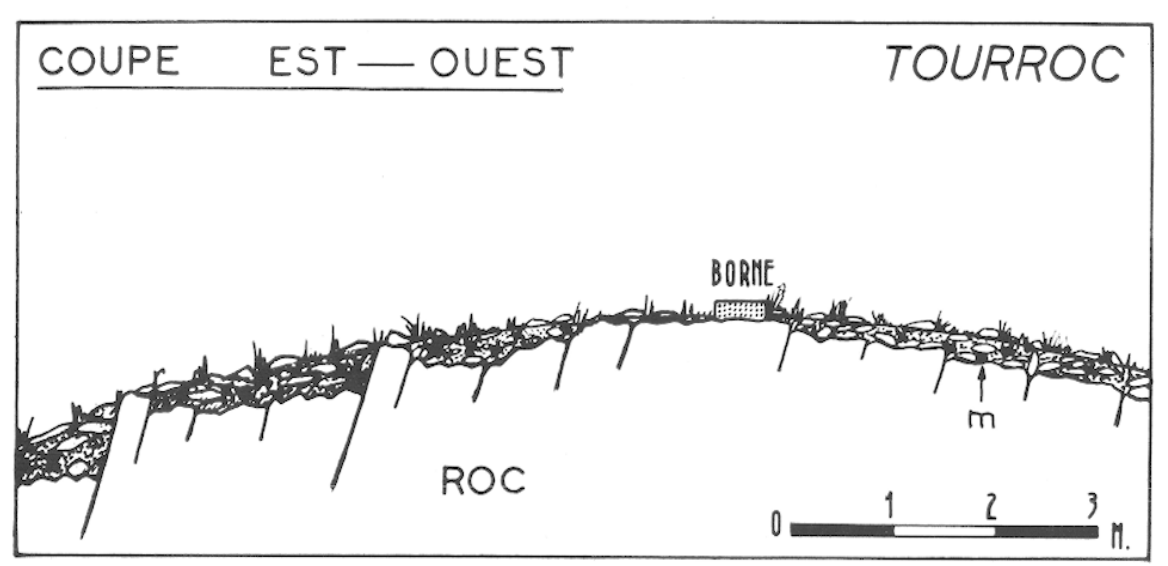

Fig. 7. - Coupe de la plate-forme terminale (croquis G. Fouel).

ce même jour des rochers de Pènetoue s'étant révélé décevant, nous décidâmes de poursuivre l'ascension du Mont-Sacon jusqu'au point culminant, le sommet de Tourroc (1541 mètres).

Les premiers petits sondages, tentés sur la plate-forme terminale à l'aide du léger matériel de fouille que nous avions emporté (piochon et pelle-pioche d'équipement de jeep américaine), nous permirent de découvrir, à une profondeur de 15 à 30 centimètres, sous l'épais tapis d'herbes, parmi les anfractuosités de la roche grise, un petit autel votif enlier (fig. 8) six moitiés d'autels et six socles, le tout en marbre blanc saccharoïde de Saint-Béat. Un lieu de culte existait donc à cet endroit.

Nous ne manquâmes pas de remonter sur ce haut lieu dès le premier dimanche de beau temps, le 11 novembre. Une nouvelle fouille, un peu plus étendue - nous disposions cette fois de deux paires d'outils légers - révéla 37 nouveaux marbres (socles et moitiés d'autels) toujours découverts de même façon.

Mais une violente lempête de neige nous força à nous réfugier dans une cabane voisine, que nous indiqua un berger, et à abandonner le chantier. Toutefois, la forte densité des ex-voto témoignait dès ce jour de l'importance du culte pratiqué sur le sommet.

Interdits par les intempéries, les travaux ne purent reprendre qu'à la belle saison de 1957.

(11) Ce cliché, qui est l'œuvre de M. Soutou, a déjà paru dans Gallia, XVII, 1959, p. 438, fig. 36.

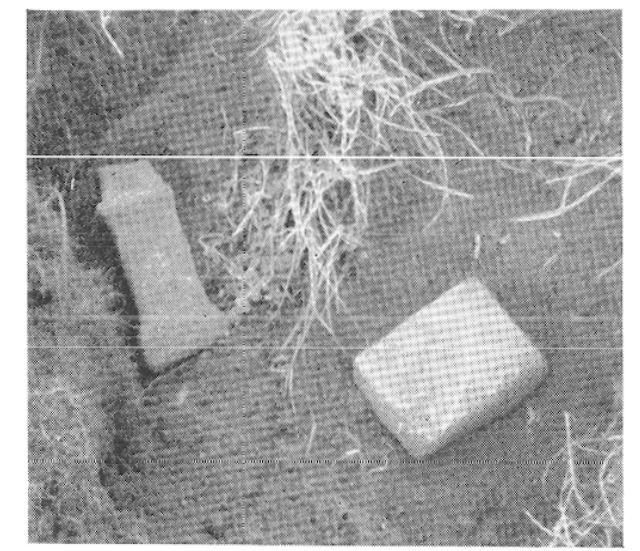

Fig. 8. - Premicr autel ct socle decouverts, en place (Photo A. Soutou).

M. le Professeur M. Labrousse, Directeur de la Région archéologique, ne pouvant, à son grand regret, parliciper à la fouille ainsi qu'il l'avait fait auparavant sur le Montlas ${ }^{12}$, nous prodigua ses encouragements et nous remontâmes les 15 et 16 juillet sur la cime de Tourroc en compagnie cette fois de deux amis toulousains fervents pyrénéistes, MM. Jacques Fourcade et Louis Cazaux. Ces deux nouvelles journées de décapage de la plate-forme terminale devaient à nouveau donner la même quantité de marbres.

Quatre journées complémentaires de travaux continus du 9 au 12 septembre 1957, clôturèrent la campagne. Si M. Soutou, empêché, n'avait

(12) M. I.nbrousse, Chronique d'information de la Xc Circonscription, Gallia VII, 1949, pp. 136-137. 


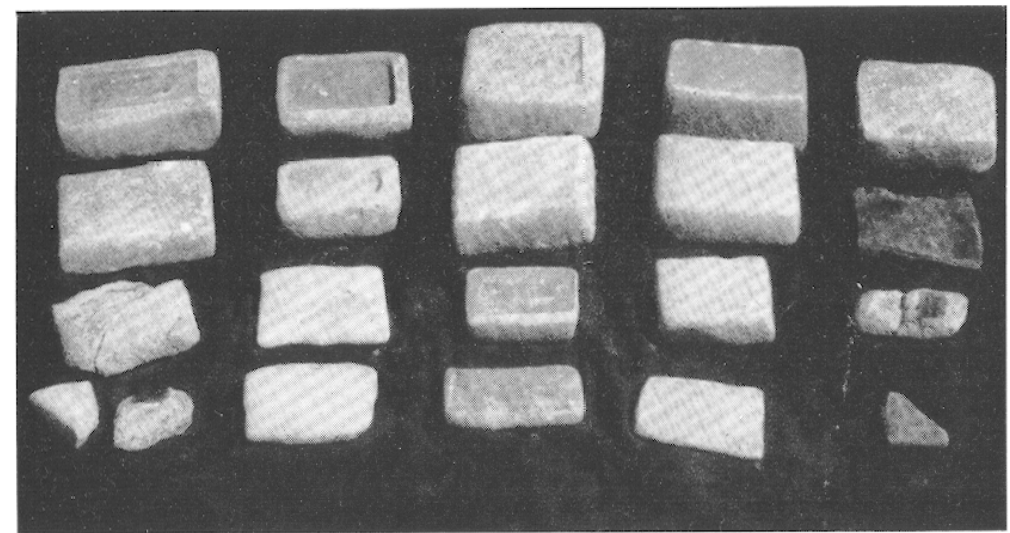

Fig. 9. - Les socles d'autels votifs (Pholo G. Fouel).

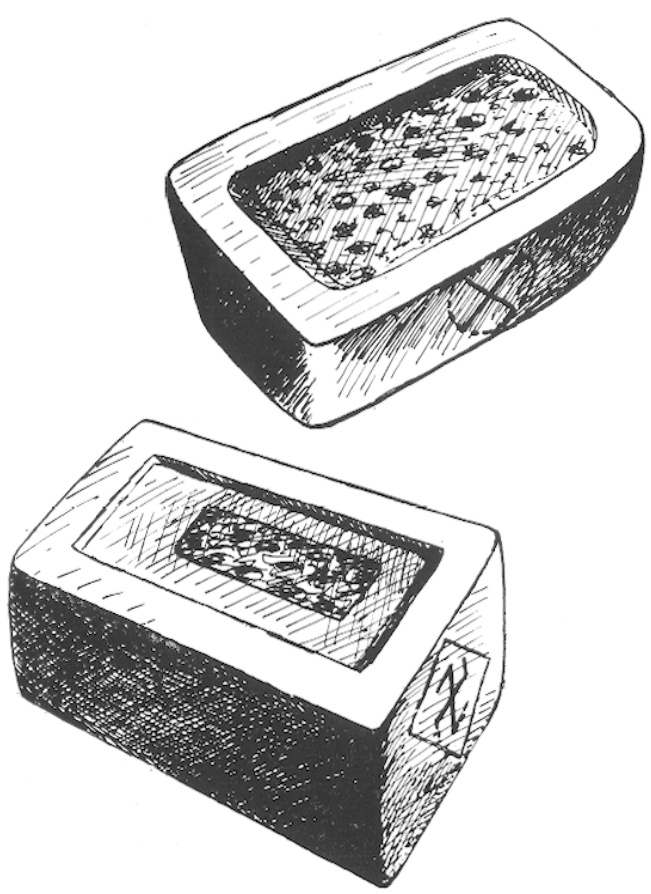

Fig. 10. - Socles portant svastika gravée (croquis (i. Fouel).

pu se joindre à MM. Cazaux, Fouel et Fourcade par contre MM. Armand Adoue, Éloi et Robert Picot, fouilleurs de la Villa de Montmaurin, apportèrent, en complément, un concours fort efficace.

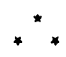

Ont été recueillis, en tout, un petit autel complet, 21 socles et 69 fragments, qui permettent d'estimer à 50 au moins le nombre total des autels votifs, ainsi que deux menus tessons de poterie, un clou de fer et une monnaic en argent ${ }^{13}$.

Cette pièce est un nummus centenionalis de Constantin 1er, frappé entre 317 et $324^{14}$. Les deux tessons paraissent provenir d'une poterie commune gallo-romaine, probablement d'un petit pichel de pâte beige. Autels et socles (sauf un) sont en marbre blanc ou gris de Saint-Béat ${ }^{15}$.

Les socles (fig. 9 et 10) : leurs longueurs, de 10 à 16 centimètres, ct leurs largcurs, de 6,5 à $12 \mathrm{~cm} .5$ correspondent à celles des bases

(13) Ces trouvailles ont été brièvement signalées par M. Labrousse, Informations de la Circonscription archéologique de Toulouse, Gallia, XV, 1957, p. 267 et XVII, 1959 , p. 438.

(14) Détermination de M. Michel Labrousse :

D./ IMP CONSTANTINUS MAX $\Lambda \mathrm{VG}$

Buste cuirassé de Constantin à droite avec le casque lauré.

R./ VICTORIAE LAETAE PRINC PERP; à l'exergue PARL.

Deux victoires debout et affrontées posent sur un autel un bouclier où l'une d'elles écrit VOT P li.

Réf. : Conse, Constantin I le Grand no 640 ; ef. Maurice, II, pp. 161-162 (ne donne qu'une pièce similaire avec au droit la simple légende IMP CONSTANTINUS AVG). Frappé par l'atelier monétaire d'Arles, entre 317 et 324 (Maurice).

(15) De la veine de cipolin blanc exploitée de Saint-Béal à Sost. Certains autels ou socles sont de qualité dolomitique, plus friable et altérable. Des fragments montrent une fois de plus qu'une fraction de la roche de Saint-Béat est particulièrement riche en feldspath métamorphique (certaines surfaces au feldspath corrodé), cf. G. Astre, Sur un fragment de 


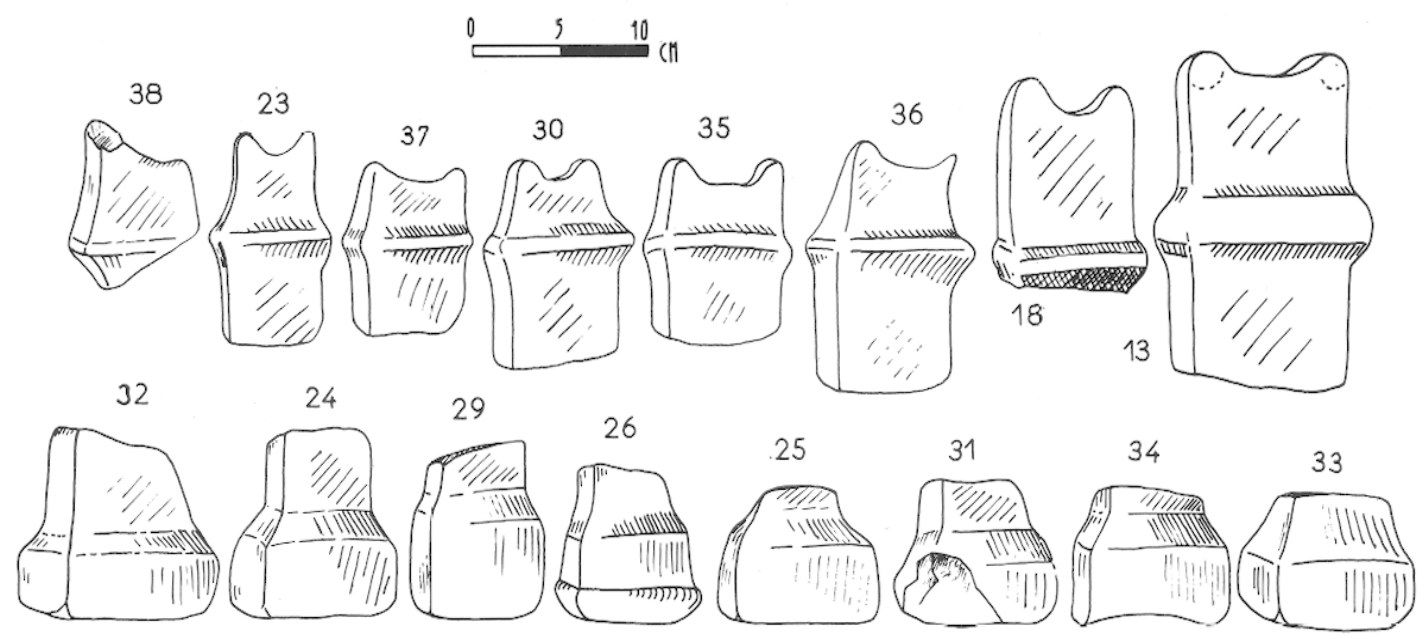

Fig. 11. - Fragments isolés d'autels votifs (croquis G. Fouet).

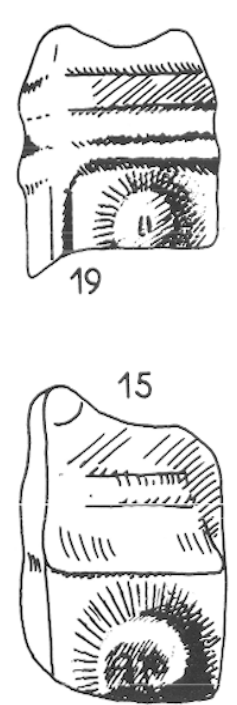

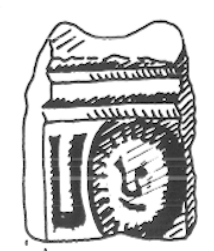
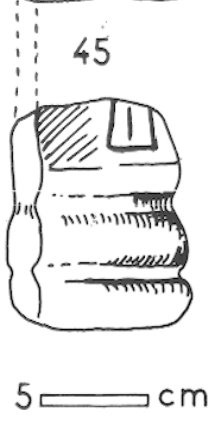
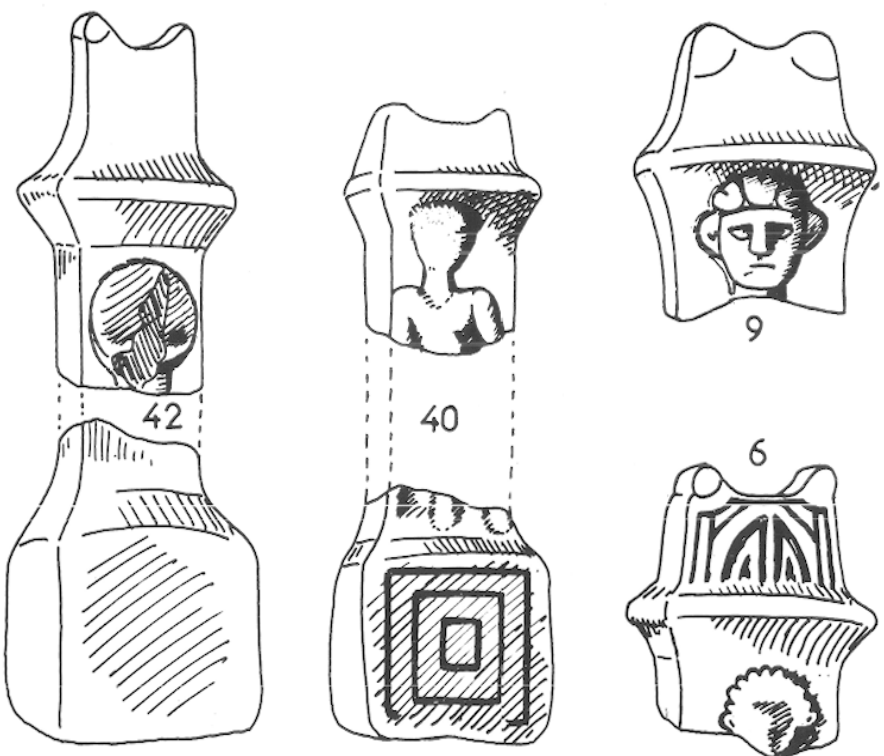

Fig. 12. - Les autels figurés (croquis G. Fouet).

d'autels. Quinze d'entre eux, épais de 2 à $6 \mathrm{~cm} .5$, d'assez bonne exécution, sont en tout point semblables à ceux que l'on rencontre dans les sanctuaires gallo-romains de la région (cf. en particulier le petit socle trouvé dans le temple de la villa de Montmaurin, fig. 18, au

marbre antique au Tuco de Cazeneuve, Bullelin de la Sociélé archéologique du Midi de la France, $3^{\mathrm{e}}$ série, I, 1931. Nous remercions très vivement M. G. Astre, Professeur de Géologie à la Faculté des Sciences de Toulouse, qui a bien voulu examiner le matérian des autels. centre $)^{16}$. Deux d'entre eux ofirent en éclairage frisant les traces de deux svastikas gravées à la pointe (fig. 10). Épais seulement de 1,5 à $3 \mathrm{~cm} .5$, cinq autres, plus frustes, ne sont que de petites dalles plates rectangulaires à bords arrondis, façonnées sans beaucoup de soins :

(16) Figalement : G. FouET, Découvertes galloromaines de Saint-Plancard, nos 24 et 25 (fig. 19-20) p. 96 in J. Laffargue-G. Fouer, Peintures romaines, vesliges gallo-romains à Saint-Plancard (HauteGaronne), Toulouse, 1948. 
ce sont des autels de fortune, taillées sans doute de la main même des dédicants.

Un dernier socle, seul, n'est pas en marbre. Il s'agit d'un rectangle de 8 centimètres sur 12 , taillé dans un plancher de calcite cristallisée en croûtes superposées : c'est le seul fragment de concrétion stalagmitique observé dans la fouille.

Aux 21 socles déjà mentionnés viennent s'ajouter 7 aulres exemplaires faisant corps avec leur autel (nos 4-10-11-26-28-43-45); ce qui porte le total à 28 , quantité qui n'équivaut à peine qu'à la moitié du nombre des autels. Force reste donc de constater l'absence d'au moins la moitié des socles, principalement des plus gros ${ }^{17}$. Comme cette absence s'accompagne de celle de nombreuses moitiés d'autels, il est possible que des fragments de marbre aient, été utilisés comme matériaux de construction par les bergers qui bâtissaient leurs cabanes sur la bordure nord des parcelles 739-74018.

Les autels - Les 69 fragments d'autels se répartissent comme suit :

1 seul autel entier, le plus pelit ( $n^{0} 1$ ),

32 moitiés d'autel paraissant se compléter deux à deux (16 autels),

21 parties supérieures isolées,

14 parties inférieures ne se raccordant pas aux précédentes,

1 fragment informe (le seul non dessiné).

Il est donc permis d'affirmer l'existence de 53 autels au minimum. Les poids varient entre $0,425 \mathrm{~kg}$ et une dizaine de $\mathrm{kg}^{19}$, les hauteurs

(17) La trouvaille sur le sommet plus élevé du Montlas (1.729 mètres) d'un socle de $27,5 \times 21 \times 17$ (soit le double du plus gros recueilli sur le Mont-Sacon) montre bien que les dévots n'hésitaient pas devant le transport à dos d'homme de marbres pesants sur les sommets (cf. M. LABrousse, Gallia, VII, 1943, p. 136). Le fragment $n^{\circ} 53$ atteste l'existence d'au moins un autel beaucoup plus gros que ceux que nous avons pu recueillir.

(18) Nous n'avons pas observé de marbres dans les murs de l'actuelle cabane de pierres seches, mais entre cette dernière et le sommet s'étend une zone abritée restée non fouillée, pouvant recéler des vestiges de précédentes constructions anciennement écroulées.

(19) Poids actuel du fragment $\mathrm{n}^{0} 12$ : $2 \mathrm{~kg}$. 625, devant indiquer un poids total d'au moins 6 kilos. L'autel auquel appartenait. le fragment no 5.3 devait peser davantage. de 13 , à, probablement, $40 \mathrm{~cm}$., les largeurs de 4,5 à $14 \mathrm{~cm}$., les épaisseurs de 4 à $10 \mathrm{~cm}$.

Dimensions et poids paraissent ainsi comparables à ceux des nombreux autels analogues retrouvés dans la région : la moyenne des hauteurs des petits autels déposés au Musée de Toulouse n'est que de $28 \mathrm{~cm}$., celle des largeurs de $11 \mathrm{~cm} .5$ seulement ${ }^{20}$. Les dévôts se sont donc contentés de puiser dans des fabrications de grande série à bon marché. Sans doute les autels, dont le dé et le socle étaient d'une même pièce, coûtaient-ils moins chers que ceux dont les deux parties avaient été confectionnées séparément. Peut-être même que, pour économiser la main d'œuvre, certains dédicants avaient fabriqué de leurs propres mains leurs ex-voto.

Un autel $\left(n^{0} \quad 7\right)$ présente sur sa surface inférieure, vers le centre du pied, un trou foré de 7 millimètres de diamètre pour 10 millimètres de profondeur, conservant des traces de rouille; M. Lizop a déjà signalé qu'en un autre lieu des Pyrénées, on avait utilisé une cheville de fer pour réparer un autel qui s'était cassé en deux en tombant ${ }^{21}$. L'intention qui se manifeste ici, de fixer un autel sur son socle, tout comme les nombreuses traces d'usure que l'on peut constater sur les angles des bases, semblent indiquer que les ex-voto devaient subir des oscillations répétées et qu'ils étaient exposés en plein air et en plein vent. Les cassures témoignent aussi de chutes probables, d'une certaine hauteur, et le fait qu'aucune réparation n'ait été effectuée sur deux fragments complémentaires - que nous avons pourtant retrouvés à proximité l'un de l'autre - peut être interprété comme la preuve de l'écroulement général des autels, après l'abandon définitif du lieu de culte. L'hypothèse d'un bris systématique des autels ne

(20) Moyennes calculées d'après les dimensions indiquées dans $\mathrm{H}$. Rachou, Calalogue des collections de sculpture el d'épigraphie du Musée de Toulouse, Toulouse, 1912.

(21) R. Lizop, Autels votifs gallo-romains découverts dans la vallée de la Neste, Bulletin de la Sociélé archéologique du Midi de la France, 1938, III, p. 46 (autel trouvé en 1937 au "Couret de Bazus": un goujon de fer émerge de la cassure, la partie supérieure de l'autel ayant disparu). 
paraît guère pouvoir être retenue : l'on s'expliquerait mal le maintien sur les lieux d'une telle quantité d'ex-voto dont aucun n'a été martelé et qu'il aurait été fort simple de faire disparaître en les envoyant se fracasser parmi rochers et pierrailles en contrebas. Du reste, le respect superstilieux des montagnards pour les Peyros Santos ou Peyros Sacrados, qui est partout resté très vif jusqu'au $\mathrm{XIX}^{\mathrm{c}}$ siècle $^{22}$, permet de penser que le sanctuaire n'a pas été volontairement détruit.

Les marbres gisaient principalement à une distance de 1 à 4 mètres autour de la borne actuellement fixée sur le point culminant, les plus nombreux se trouvant, en contrebas du côté nord-est, pêle-mêle avec des dalles et des éclats de roche du sommet. Un pelil socle brisé en 3 morceaux séparés marquait, à $7 \mathrm{~m}$. 50, le point de chute le plus éloigné et le plus bas. Il n'y avait pas de marbres à moins d'un mètre de la borne : il semble que sur son emplacement se soit dressé en plein air une sorte de podium de pierres sèches supportant les autels.

Une telle table à offrandes était indispensable si, selon toutes probabilités, des moutons, comme de nos jours, passaient l'été sur le vaste pacage terminal du Mont-Sacon : nous avons pu constater que le troupeau s'assemblait tous les soirs sur le sommet de Tourroc pour y passer la nuit ${ }^{23}$. Il était donc nécessaire, pour que les offrandes restent hors de portée des animaux, que soit édifié un support massif d'une hauteur minimum d'un mètre.

Lorsque, par la suite, ce support se fut, écroulé, les marbres qui avaient été déjà érodés par les intempéries furent piétinés par les ovins, mêlés à leur fumier et progressivement

(22) A Sost et à Saint-Pé-d'Ardet, les autels paiens restaient vénérés dans l'église; les autels en place recevaient toujours des suppliques aussi bien à PeyrosMarmés (au col de Couret-Médan) qu'entre Nistos et IIéchettes : A. du MÈgE, Monumenls religieux des Volces-Teclosages, des Garummi et des Convenae, Paris, 1814, pp. 343. A. du MÈGE, Archéologie pyrénéenne, t. II, Toulouse, 1860, pp. 153, 340 .

(23) M. le Maire de Sacoué et les bergers connaissaient bien le refuge nocturne des brebis, bien serrées sur le pointement rocheux surtout les nuits de clair de lune. ensevelis sous les herbes où se poursuivit le processus de destruction chimique.

$$
* *
$$

Malgré celte succession de dégradations, près de la moitié des autels présentent encore des attributs votifs bien discernables, localisés sur leur face antérieure (dé, base et couronnement). A peine larges de 3 à 5 centimètres, les côtés latéraux du dé paraissent être restés bruts, comme les faces postérieures. Seul le plus gros des autels était inscrit ( $\left.n^{\circ} 12\right)$ bien que la largeur de son champ épigraphique n'atteigne que 11 centimètres. Larges seulement de 3,5 à $9 \mathrm{~cm}$. 5, les autres dés se prêlaienl moins à des dédicaces fortement gravées qu'à des figurations ou à des symboles stylisés. L'utilisation de peinture ${ }^{24}$ et de gravure légère à la pointe ${ }^{25}$ apparait probable, non seulement sur les dés actuellement lisses, mais aussi sur les bases pour ajout des signes de consécration.

La représentation graphique de tous les fragments d'autels retrouvés dispensera d'un fastidieux inventaire descriptif : nous avons dessiné séparément d'une part les autels figurés, d'autre part les autels à champ gravé et inscrit.

Figurations humaines et végétaux stylisés se partagent en proportion à peu près égales les auiels figurés :

1) Personnage en pied et série de bustes, dont les têtes seules subsistent, composent la série des figurations humaines (fig. 12).

Avec la section disparue de l'autel $\mathrm{n}^{0} 40$ manque la partie médiane de l'homme jeune et musclé représenlé debout, s'appuyant peutêtre sur un bâton. Trois carrés ou rectangles emboîtés décorent la base.

Parmi les têtes, si nulle observation n'est

(24) Bertrand SAPÉne, Autels votifs, atelier de marbriers et sanctuaire gallo-romains découverts à Saint-Bcat (Haute-Garonne) en 1946, Revue de Comminges, t. LVIX, 1946, p. 313. E. EychenNe et G. Fouer, Découvertes gallo-romaines à SaintGaudens, Revue de Comminges, LXXII, 1959, pp. 107, 111.

(25) Celle-ci, attestée, mais très endommagèe par l'érosion (cf. nos 1, 21, 27, 42, 43, 47). Les deux procédés, gravure à la pointe et peinture, pouvaient d'ailleurs se combiner. 

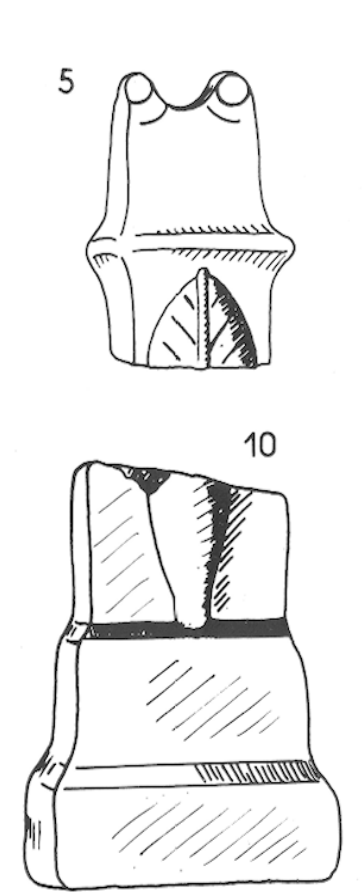

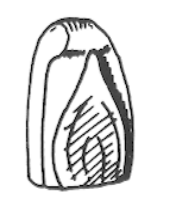

52
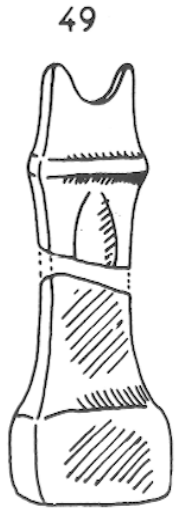
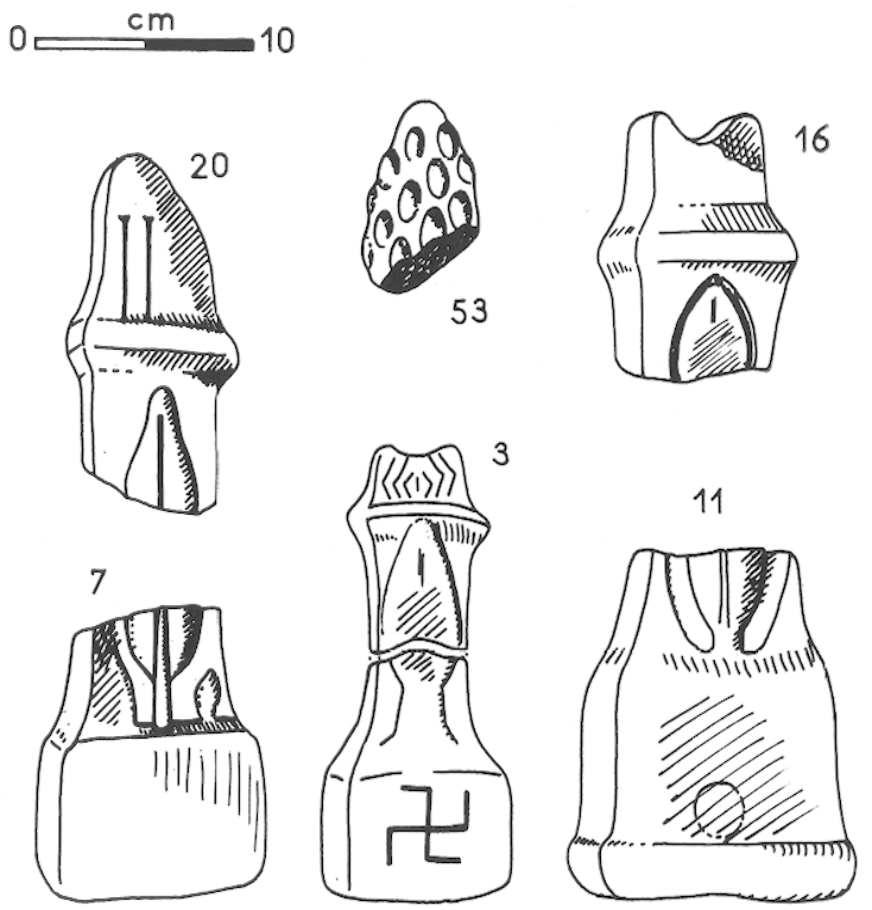

Fig. 13. … Autels décorés de végétaux stylisés (croquis $(x$. Fouet).

possible sur celle trop gravement endommagée du no 42, par contre demeure conservée en bon état celle du $n^{0} 9$ : les oreilles sont bien marquées et la chevelure traitée ḋ la mode indigène ${ }^{26}$. La tête figurée sur le $\mathrm{n}^{0} 6$ semble de même facture; sur le couronnement, au dessus, deux pousses végétales se détachent dans un encadrement ${ }^{27}$.

De grandes analogies rapprochent les trois autres têtes des autels nos 15-19-45. De même forme générale ces trois marbres à double corniche, tout comme un autre petit autel découvert à Castillon ${ }^{28}$ semblent provenir d'un même lieu de fabrication au style bien particulier.

Ces têtes reproduisent, en effet, avec une

(26) Comparer, par exemple, avec celles figurées : Espéknndiet; Recueil..., II, no 882 ou J.-J. Hatt, Les monuments funćraires gallo-romains du Comminges et du Couserans, Annales du Midi, LIV-LV, pl. XV, f. 42 (Saléchan) et pl. XVI, K-78 (Garin).

(27) Motifs analogues sur le couronnement d'un autel de Bramevaque dédié à Jupiter : J. SACAzE, Inscriptions antiques des Pyrénées, Toulouse, 1892, 393. Pousses également, au même emplacement, sur un autel d'Ilheu : M. LABrousse, Gallia XII, 1954, p. 220.

(28) J. SACAZE, op. cit., no 352. similitude vraiment frappante, les petits visages ronds à peine larges de 6 à 10 centimètres, traités de même en faible relief sur le rocher du Mail d'éras Higouras, le sanctuaire gallo-romain des carrières de St-Béat ${ }^{29}$.

2) Neuf dés d'autels conservent la figuration d'une pousse végétale stylisée (fig. 13). Une vingtaine d'autres autels, fabriqués vraisemblablement à St-Béat comme les précédents et provenant d'une douraine de localités commingeoises toutes situées dans les hautes vallées de la Garonne et de ses affluents, présentent des décors analogues ${ }^{30}$. La nature exacte et la destination de ces schématisations

(29) B. SApìne, op. cil., pp. 316-318, fig. 17-18. M. LABRousse, Un sanctuaire rupestre gallo-romain dans les Pyrénées, Mélanges Charles Picard, Paris, 1949, pp. 488-490.

(30) 5 à la Croix de l'Oraison à Tibiran; Collection de $M$. le baron d'Agos à Tibiran (Hautes-Pyrénées), Congrès archéologique de France, $\mathrm{XVI}^{\mathrm{e}}$ session, AgenToulouse, 1874, Paris, 1875, $\$$ II, Autels sans inscription $\mathrm{n}^{\mathrm{s}}$ 14-22-25-33 et Invenlaire du Musée de Comminges (Rapport sur les fouilles de Saint-Bertrand-deComminges en 1931), nos 11-13-15-19-23.

1 à Géry près Saint-Béat: J. SACAze, op. cil., no 315 (Cléry doit être lu Géry).

1 à Castillon d'Arboust : J. SACAzE, op. cit., no 351. 

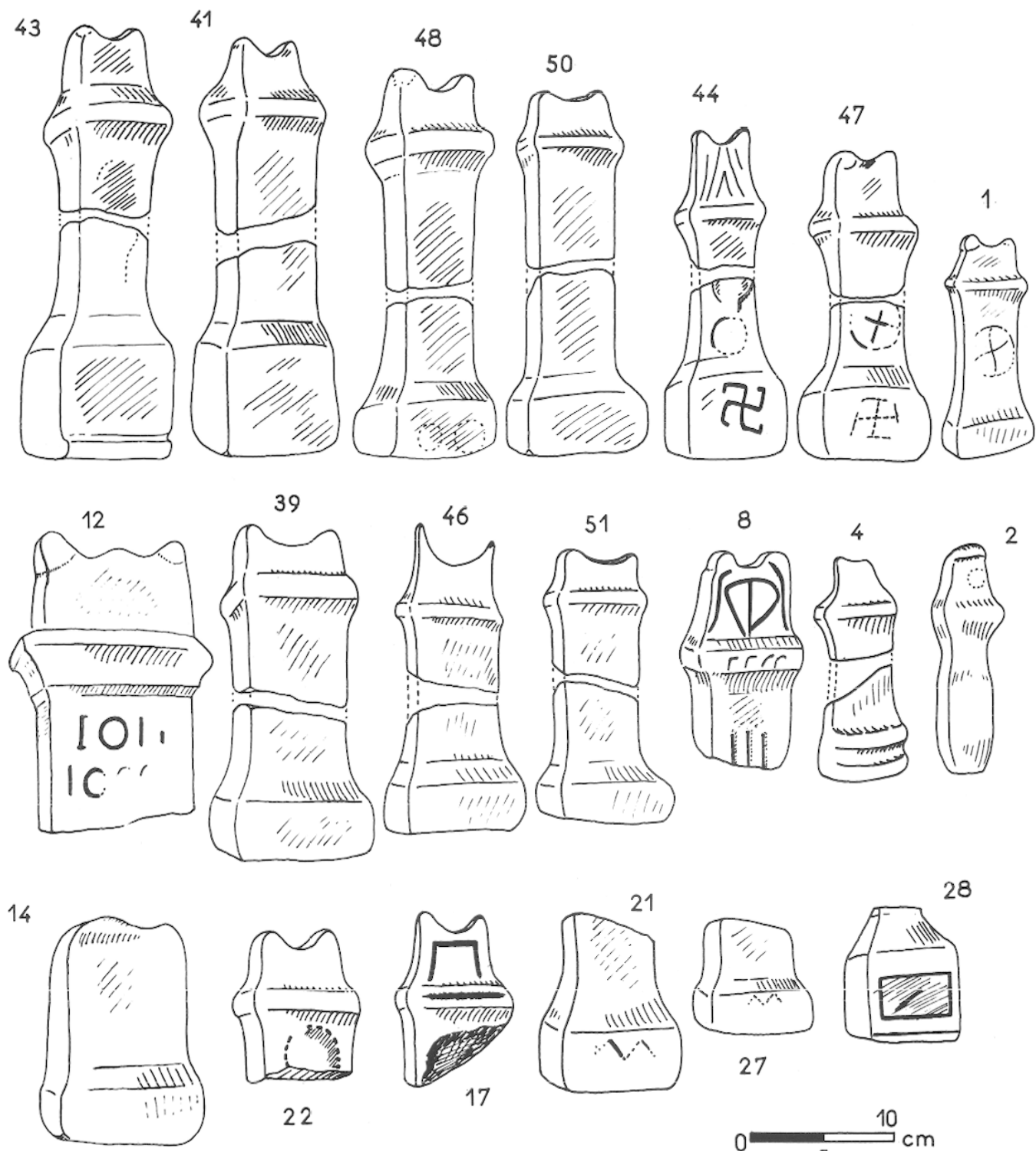

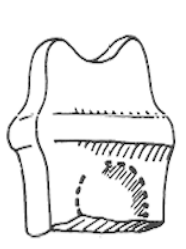

22

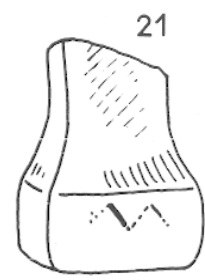

17
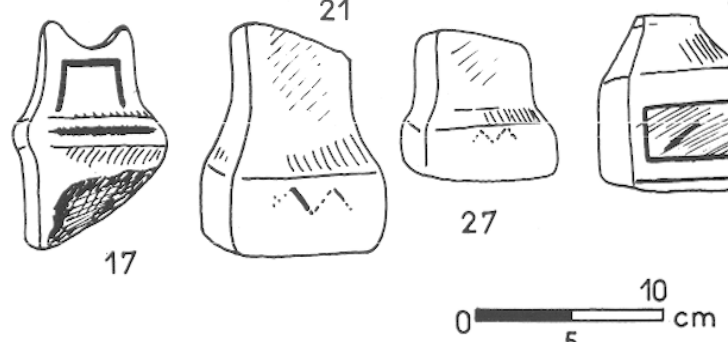

Fig. 14. - Autels votifs variés (croquis G. Fouel).

1 dans le Val d'Aran : J. SAc.Az, op. cit., p. 469.

3 à Sost : Espéraxpré; op. cil., nos 864 et 865 , 1 et 2. Cf. A. du Mi:Gr, Archéologie pyrénéenne, II, p. 340 .

1 à llheu: Gallia, X1I, 1954, 1, p. 220.

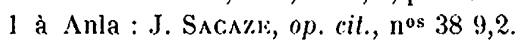

1 à Juzet : J. Castex, Inventaire archéologique du pays de Luchon, Revue de Comminges, I.XXI, 1958 , p. $111, \mathrm{n}^{\circ} 56$.

1 à Ladivert, Espérandiev, op. cil., 865, 3. Cf.

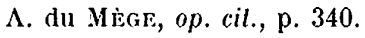

1 à Loures-Barousse.

1 à Mont-de-Galié.

1 à Argut-Dessus : A. du Mícke, op. cil., II, p. 347 et III, p. 109. végétales étaient restées jusqu'à présent énigmatiques; mais une récente découverte vient les éclairer d'un jour nouveau : les fouilles de 1958 viennent de révéler, en effet, parmi les vestiges du temple de la Villa d'Arnesp à Valentine (Hte-Garonne) le petit autel votif de la figure 17 , encore inédit ${ }^{31}$.

On peut nettement distinguer, en relief, sur

(31) En marbre gris saccharoïde de Saint-Béat, hauteur : 26 centimètres, largeur : $13 \mathrm{~cm}$. b, epaisseur : 8 cm. 5. Cf. G. Fouer, Rapport de fouilles 1958 
le dé, un arbre ou un arbuste planté dans une sorte de vase, autel ou puteal à margelle, émergeant de la base. Ce motif est semblable à celui qui décore un autre autel, depuis longtemps connu, puisqu'il fut acquis, dès 1821, par A. du Mège qui le déposa au Musée de Toulouse ${ }^{32}$, mais qui, jusqu'ici, n'avait qu'assez peu attiré l'allention : le dé de ce petit monument présente de même un arbre ou un arbuste planté dans un autel ou puteal à base et margelle $^{33}$. Ce sont là, à n'en pas douter, représentations d'arbores sacrae ${ }^{34}$, de même d'ailleurs, que toutes les pousses d'une facture moins soignée qui, sur les autres autels, paraissent émerger du réceptacle quadrangulaire formé par la base (cf. nos 7 et 10 par exemple, fig. 13).

Ce sont ces mêmes arbres sacrés que l'on peut reconnaître également sur un marbre votif d'Ardiège (Hte-Garonne) qui représente un " personnage assis tenant des deux mains un arbre au feuillage stylisé $)^{35}$ ou sur un exemplaire en provenance d' $\Lambda$ pt (Vaucluse) qu'orne, semble-t-il, un arbre en pied ${ }^{36}$ ou encore sur l'autel de Saint-Geniès-de-Limbaud, en Gironde, où sont dislinctement figurés deux végétaux dont les tiges surgissent de la base, comme d'un sol ${ }^{37}$. C. Jullian avait bien noté à propos de ce dernier monument qu'il s'agissait " sans doute d'un arbre sacré comme les Anciens en ont figuré si souvent sur leurs bas-reliefs $\Perp^{38}$.

Ces autels recueillis sur le sommet de Tourroc n'étaient pas offerts à un arbre qui ne pouvait vivre sur cet âpre pointement rocheux : leurs

(transmis à la Direction de l'Architecture, au Comité archéologique du CiNRS, à la Direction de la Région archéologique).

(32) A. du Mìck, Archéologie pyrénéenne, II, Toulouse, 1860 , p. $340:$ l'un des 3 petits autels conservés à l'église de Sost comme Pierres Sacrées. II. Racrot, Catalogue Musee Toulouse, no 297.

(33) Autre représentation probable d'autel rond, mais sans margelle, d'où sort un végétal. J. SACAzE, op. cit., no 117 , p. 189 et no 23, Inventaire Musée de Comminges.

(34) E. Saglio, art. Arbores Sacrae, du DarembergSaglio-Pothier ; Diclionnaire des Antiquités, fig. 439440-448-450.

(35) Espéranditu, op. cil., 8118.

(36) Ibidem, 242.

(37) A. Brutails, Autel représentant un arbre, Revue d'Etudes Anciennes, 1906, p. 261-262.

(38) Ibidem, p. 262, en note. figurations d'arbustes ou pousses, devaient être simplement considérées comme des verbena $^{39}$. Les offrandes de végétaux sacrés ne sembleraient pas inconnues du Midi de la Gaule : vases et jarres à fond percé disposés près des autels-foyers décorés, retrouvés sur l'oppidum de la Roque près de Montpellier ${ }^{40}$ en pourraient bien attester la pratique dès les IV-III ${ }^{\mathrm{e}}$ siècles avant J.C. Un autre vase à fond percé figure aussi dans un mobilier rituel de La Tène III retrouvé à VieilleToulouse ${ }^{41}$. Des vases de même caractère devaient aussi, vers le milieu du ive siècle après J.G., voisiner dans le temple de la villa de Montmaurin (Hte-Gne) avec une sorte de cuvette a offrande quadrangulaire de terre cuite pouvant fort bien avoir convenu au même usage ${ }^{42}$. Peut-être aussi est-ce la face antérieure, consacrée d'une svastika en relief, d'une telle auge en terre cuite qui vient d'être récemment découverte à Toulouse ${ }^{43}$.

Dans les Pyrénées une cuve à fond percé apparait au moins, taillée dans le roc au centre du "léménos" de Géry près de Saint-Béat"44 tandis qu'un "petit socle cylindrique creux

(39) A. Piganiol, art. Verbena du Dicl. des Anliq. (40) P. I.arnerer, L'oppidum préromain de La Roque, commune de Fabrègues (IIérault), Gallia, XV, 1957, pp. 25-34. P. LARDERET, Les découvertes archéologiques de l'oppidum de La Roque (Hérault), Contribution à l'étude des croyances religieuses préromaines, Revue d'Eludes Ligures 1957, pp. 76-78. Ces vases à fond percé pourraient autoriser d'étroits rapprochements avec ceux de la Crète minoenne dont l'influence semblerait s'être ètendue jusqu'en Espagne sur le pourtour de la Méditerrance : cf. Ch. PICARD, Les origines du polythéisme hellénique, Paris, 1930, I, p. 151. R. VAllois, Autels et culte de l'arbre sacré en Crête, Revue des Kludes Anciennes, 1926, p. 123-128.

(41) G. Fouet-R. Mounié, Le puits funćraire no 4 de Vieille-'Toulouse, Pallas 1960 (sous presse). Des amphores décolletées et percées seraient aussi à rapprocher.

(42) G. Foukr, Puits funéraires d'Aquitaine : Vieille-Toulouse, Montmaurin, Gallia, XVI, 1958, pp. 177-178, ainsi que trouvailles encore inédites des fouilles de la Villa.

(43) Trouvaille de M. Villeval, mentionnce par M. Labrousse, Informations de la circonscription de Toulouse, Gallia 1959, p. 430, fig. 27.

(44) R. I.rzop, Le Comminges et le Couserans avanl..., pp. 156-157. 
de terre cuite "figurait parmi les offrandes du sanctuaire de Montsériét5.

Deux exemples pourraient témoigner de la persistance dans les vallées commingeoises des antiques pratiques d'offrandes végétales : jusqu'en 1821 l'église de Sost conserva comme Pierres Sacrées des autels votifs portant représentations d'arbustes ${ }^{46}$ tandis qu'à même date les autels demeurés en place au lieu dit PeyrosMarmés restaient honorés du dépôt d'une branche d'arbre, accompagné d'une prière de la part des passants au col de Couret-Médan ${ }^{4}$.

En dehors des dés, des représentations de symboles végétaux figuraient aussi sur des couronnements : le no 53 , en particulier, provient, semble-t-il, de la partic supérieure d'un autel de même modèle que ceux déjà trouvés à Sost et à Ladivert, actuellement déposés au Musée de Toulouse ${ }^{48}$, dont les sommets conservent, encadré par les enroulements, le pointement conique en forme de pomme de pin d'une sorte de bourgeon verticalement strié, semble-t-il, sur l'un, lisse sur l'autre. Un arbuste stylisé figure sur le champ de ces deux autels.

Peut-être est-ce, sur le couronnement de l'autel no 6 (fig. 12), représentation analogue (à moins qu'il ne s'agisse de deux pousses ou de deux faînes accolées dans leur involucre ?). L'autel $n^{0} 3$ (fig. 13) dont le couronnement semble copié sur celui d'un autel d'Arlos ${ }^{49}$ porte une svastika gravée sur la base.

Bien que les autels peints ou gravés aient constitué la grosse masse des ex-voto, les intempéries et les cassures n'ont malheureusement laissé subsister qu'assez peu de figura-

(45) Ch. L. Frossard fils, Le Paganisme dans les Hautes-Pyrénées, Bulletin de la Societé Ramond, 1870 , p. 172 (énumération sans précision des objets trouvés avec les autels et les socles).

(46) A. du M̀̀GE, Archéologie pyrénéenne, II, p. 340.

(47) A. du Mìge, Monuments religieux..., p. 306 ; P. de Gorsse-R. Lizor, Le carnet de route d'un archéologue commingeois vers 1880, Mémoires de la Sociélé archéologique du Midi de la France, XIX, pp. 226-227; M. Labrousse, Informations de la Xe Circonscription, Gallia, VII, 1949, p. 136.

(48) Espérandieu, Recueil, II, 865, 1 et 3 . A. du Mìk, cí. note 42 ci-dessus.

(49) J. Sacazr, op. cil., no 288 (le dé représente un personnage nu tenant pierre et bâton). tions discernables (fig. 14). Le motif le plus souvent reproduit consistait dans la rouelle croisillonnée (nos 1-47 au moins) que nous retrouvons sur un autcl du sommet du Montlas $^{50}$, sur un autel de la Villa de Montmaurin (fig. 18) et sur l'arrière de la base de l'autel d'Arnesp (fig. 17 $)^{51}$.

Sur le dé de l'autel $n^{0} 8$ sont gravées des rainures verticales, qui imitent les cannelures en relief que l'on voit sur le dé d'un autel conservé au Musée de Saint-Bertrand ${ }^{52}$. Quelques décors subsistent, sur des couronncments : sorte de triangle médiané inversé sur l'autel no 8 que l'on retrouve sur un autel d'Iluos de meilleure facture ${ }^{53}$; motif tectiforme de l'autel 17 qui a été souvent gravé à la même place sur des autels pyrénéens ${ }^{54}$, triangles imbriqués du $n^{0} 44^{55}$, sorte de boulette en relief $d u n^{0} 2^{56}$. Sur des bases apparaissent un rectangle $\left(\mathrm{n}^{0} 28\right)^{57}$ et une svastika (n ${ }^{\text {os }} 44$ et 47 ).

Bien qu'en mauvais état, l'unique inscription qui a été conservée, celle de l'autel no 12 n'en présente pas moins un intérêt capital. Malgré la corrosion du marbre la partie la plus significative de la dédicace est encore lisible : on distingue en effet à la première ligne les trois lettres bien détachées I O M : I (ovi) O (ptimo) M (aximo). A Jupiter très bon, très grand. Voici nommément désignée la toute puissante divinité invoquée sur ce sommet à qui devaient être également consa-

(50) Il s'agit de l'autel cité dans Gallia, VII, 1949, p. 136 dont le décor s'est révélé par lumière rasante.

(51) 'lardivement d'autres croisillons maladroitement tracés à la pointe furent ajoutés à la rouelle : cet additif est fort visible sur le marbre.

(52) Inventaire..., n $\mathrm{n}^{*} 20$ (Collection d'Agos, $\mathrm{n}^{\circ} 30$ ).

(53) J. Sacaze, op. cit., no 211.

(54) J. SACAZE, op. cit., nos 116-326-389... (simple ou répété).

(55) Même ornementation sur un couronnement d'autel à Jupiter de Bramevaque. J. SAcAzE, op. cit., II $392,2$.

(56) Se retrouvent sur la corniche d'un autel du Musée de Saint-Bertrand-de-Comminges (Inventaire..., $n^{\circ}$ 85). Tous nos remerciements vont à $M$. Robert Gavelle, Conservateur adjoint dı Musée, qui nous communiqua fort aimablement des renseignements sur plusieurs autels, dont celui-ci.

(57) Motif similaire : J. SACaze, op. cil., p. 190. 

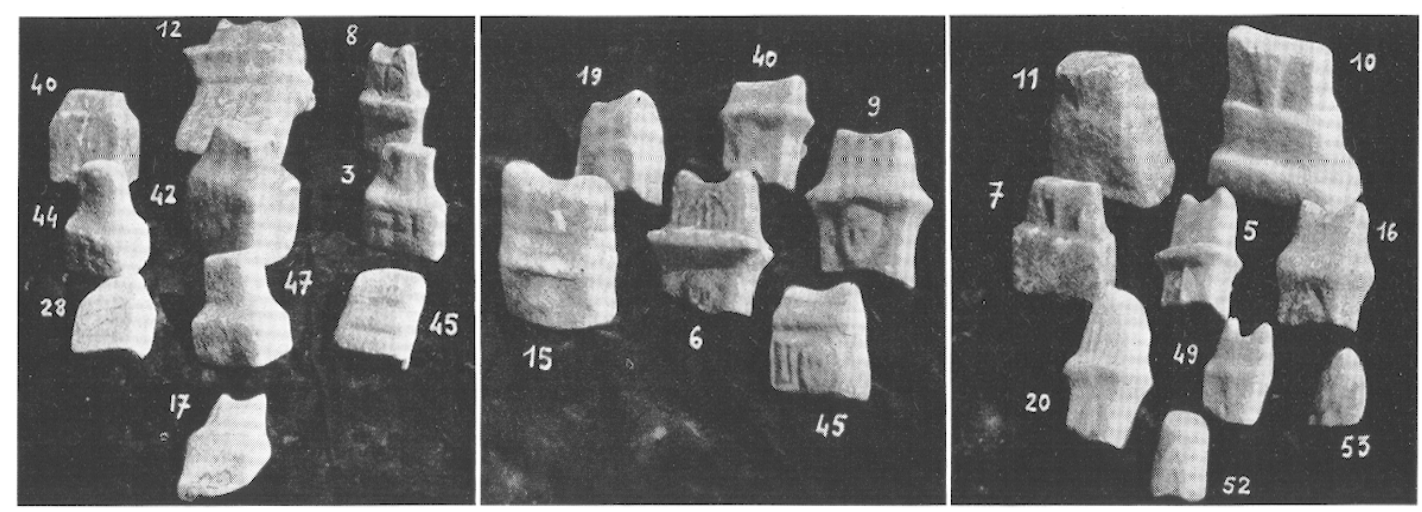

Fig. 15. - Quelques fragments d'autels (Photo G. Fouel).

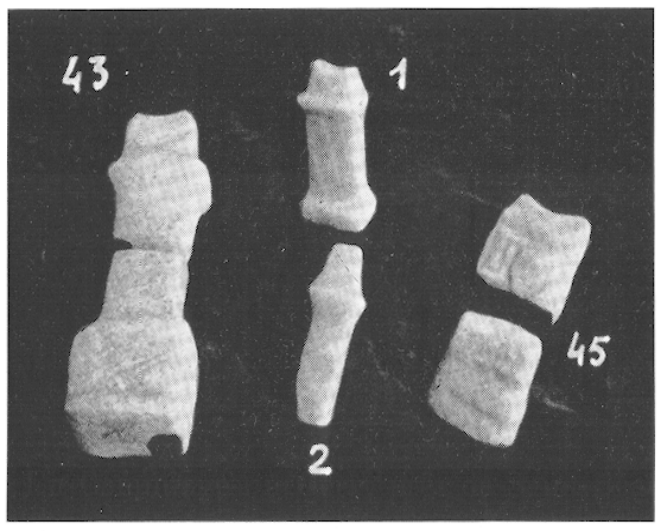

Fig. 16. - Quelques autels (Photo G. Fouet).

crées les différentes représentations symboliques ornant, l'ensemble des ex-voto.

Les végétaux stylisés ne sont pas sans rappeler l'importante collection de bractéoles d'argent consacrées à Jupiter découverte à Vichy en 1864-65. "Ces lamelles d'argent, très minces ne se ressemblent pas. Hautes de 5 à 17 centimètres, elles représentent presque toutes la grossière découpure d'un arbre; plusieurs n'en ont qu'une feuille : c'est l'arbre réduit à sa plus simple expression. Elles portent des figurations de Jupiter le plus souvent... Qu'il soit isolé, complet ou réduit à son plus simple élément, l'arbre de nos lamelles est un symbole. C'est l'ex-voto même. ${ }^{58}$

En Comminges, à Géry, près de Saint-Béat,

(58) Ch. Rossignol-A. Bertrand, Notice sur les découvertes faites à Vichy et en particulier sur les bractéoles votives d'argent, Bullelin de la Socielé d'Emulalion de l'Allier, XVIII. L. Bonsard, La un autel orné d'un arbre stylisé est consacré à Jupiter et à Minerve ${ }^{59}$. Des autels portant également la figuration d'un arbre proviennent des sanctuaires d'Arnesp ${ }^{60}$ et d'Ilheu ${ }^{61}$, qui étaient consacrés à Jupiter. G'est surtout à la Croix de l'Oraison près de Tibiran, où ont été faites les lrouvailles les plus nombreuses -après celles du Mont-Sacon - que l'on observe des stylisations végétales associées à la dédicace $F$ ago $D e o^{62}$. Cette même dédicace se retrouve à Ladivert, près de Saint-Béat où un autel était décoré d'un arbre ${ }^{63}$. Enfin à Deaux, près de Vézenobre (Gard), un autel portant une dédicace à Jupiter présentait « du côté opposé un vase contenant des feuilles et des fleurs $)^{64}$.

Il est possible, comme l'avait noté C. Jul-

Gaule thermale, Paris, 1908, pp. 283-284, fig. 31 (p. 284 : autres trouvailles de feuilles métalliques en Gaule). D. Morler, Vichy gallo-romain, Vichy, 1957, p. 280-284, fig. 183-190.

(59) J. SACAze, op. cil., no 315 (déposé au Musée de Toulouse, Catalogue Rachou, 191\%, no 240).

(60) Ch. LÉCRIVAIx, Note sur une inscription romaine de Valentine, Bulletin de la Sociélé archéologique du Midi de la France 1903-1906, p. 326. F. Espérandieu, Inscription latine du I ${ }^{\mathrm{cr}}$ siecle trouvée à Valentine, Bulletin de la Societé Nalionale des Antiquaires de France, 1906, p. 149. Rouelle et svastika précisent aussi, comme nous le verrons plus loin, que l'autel de notre figure 17 était bien dédiè à Jupiter.

(61) Autel à I $O M$ d'Ilheu : J. SAcazk, op. cil., n० 391 .

(62) J. SACAze, op. cit., nos 116-117-118.

(63) $\Lambda$. du Mìge, Archéologie pyrénéenne, I, II, pp. 340,350 ; J. SACaze, op. cit., no 282 ; Espérandieu, Recueil II, 865, 3.

(64) Espérandieu, op. cit., 6853. 

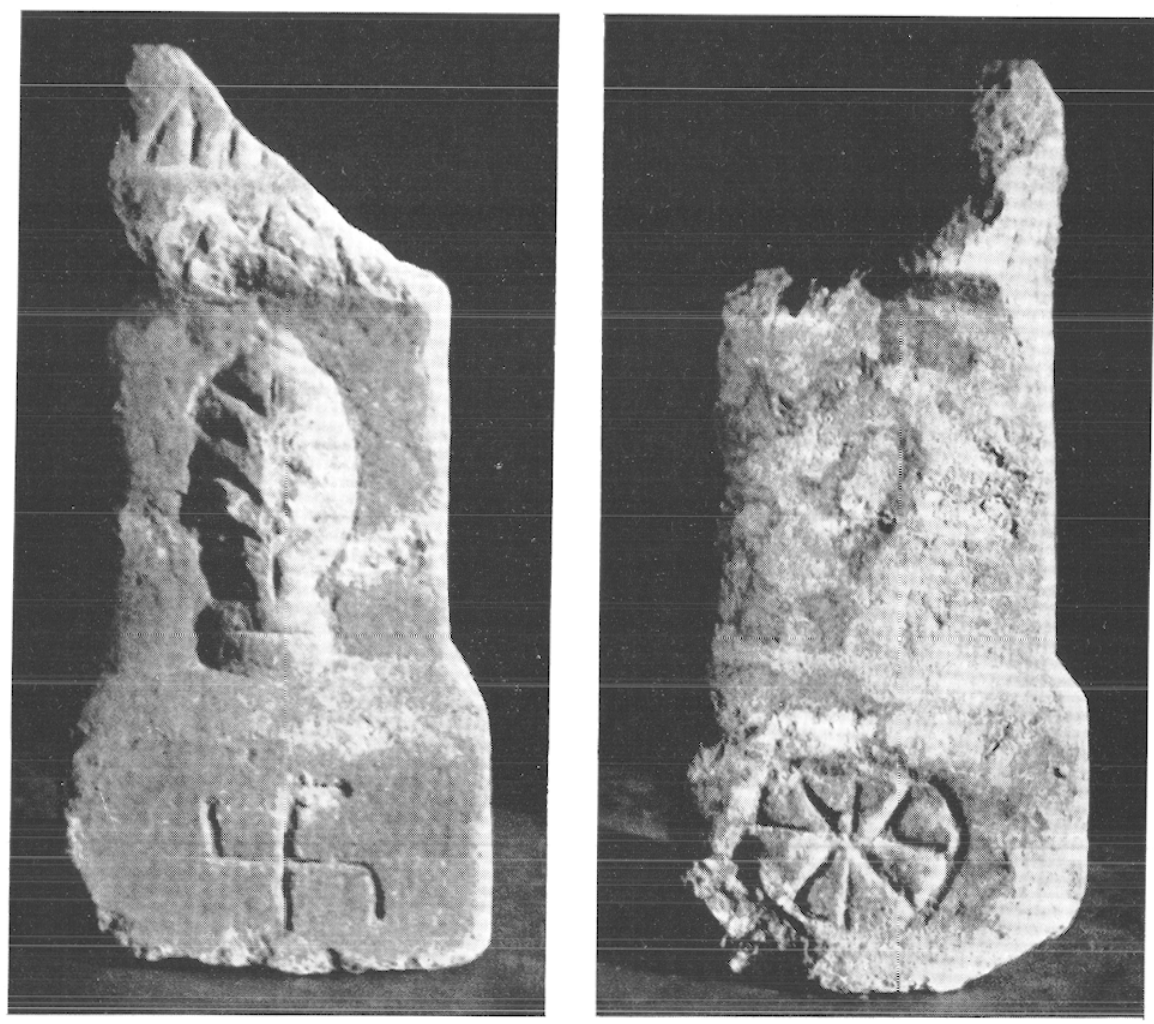

Fig. 17. - Autel votif du temple de la Villa d'Arnesp à Valentine : face et revers (Pholo G. Fouet).

$\operatorname{lian}^{65}$, que les végétaux stylisés des autels pyrénéens soient des "feuilles ou des fruits de hêtre ", comme semble le confirmer par ailleurs la formule Fago Deo. Or, sur le mont Esquilin, dans l'ancienne Rome, le Hêlre était consacré à Jupiter ${ }^{66}$, tandis qu'en Grèce la Thessalie révérait Zıús Irrós, les mols fagus et yrrós étant unis, comme le font remarquer Ernout et Meillet, par l'idée commune d'arbres à fruits comestibles ${ }^{67}$. De même que le chêne à glands comestibles, première nourriture des habilants des lieux où il poussait, fut consacré à Jupiter, père des Dieux et des hommes, de même le hêlre, arbre vital de l'ancienne économie pyrénéenne, fut-il l'objet d'une vénération au moins égale.

(65) Cf. note 38.

(66) S. P. Festus, De verborum significatione, éd. Müller, Leipzig 1886, p. 87 : sacellum Jovis in quo fuit fagus arbor quae Jovis sacra habebatur ; également : Varron, De ling. lat, V, 49 et 152.

(67) Voir F. Finnout et Mrillete, Diclionnaire Filymologique de la Langue Latine, Paris, édition 1951, p. 380 .
L'amande blanche de la faîne, riche en corps gras el dont on extrait une bonne huile de table, est comestible pour l'homme. Porcs et volailles en sont avides. Mais le hêtre, qui ne fructifie qu'à un âge avancé (de 50 à 80 ans), ne donne des faînées qu'irrégulièrement. "Presque tous les arbres ne produisent des fruits en abondance que de deux années l'une : ccla est surtout vrai du hêtre" dit Pline ${ }^{68}$. Les faînées, en réalité, ne semblent vraiment abondantes que tous les 5 ou 6 ans, quelquefois même tous les 15 ou 20 ans seulement.

Il est donc compréhensible que la puissance génératrice de cet arbre nourricier formant le manteau forestier du Mont-Sacon se soit trouvée sollicitée par des dévots intéressés.

La rouelle croisillonnée ornait plusieurs dés. Roues et rouelles sont en Gaule romaine attribut constant de Jupiter et des divinités à la roue portent la dédicace : $I O M^{69}$. Cette

(68) Pline t.r: Jeune, Naluralis Historia, XVI, 7. (69) C. Jullias, Itistoire de la Gaule, VI, p. 35 et $\mathrm{n}^{\circ} 2, \mathrm{~S}$. Reinach, Bronzes figurés de la Gaule romaine, 


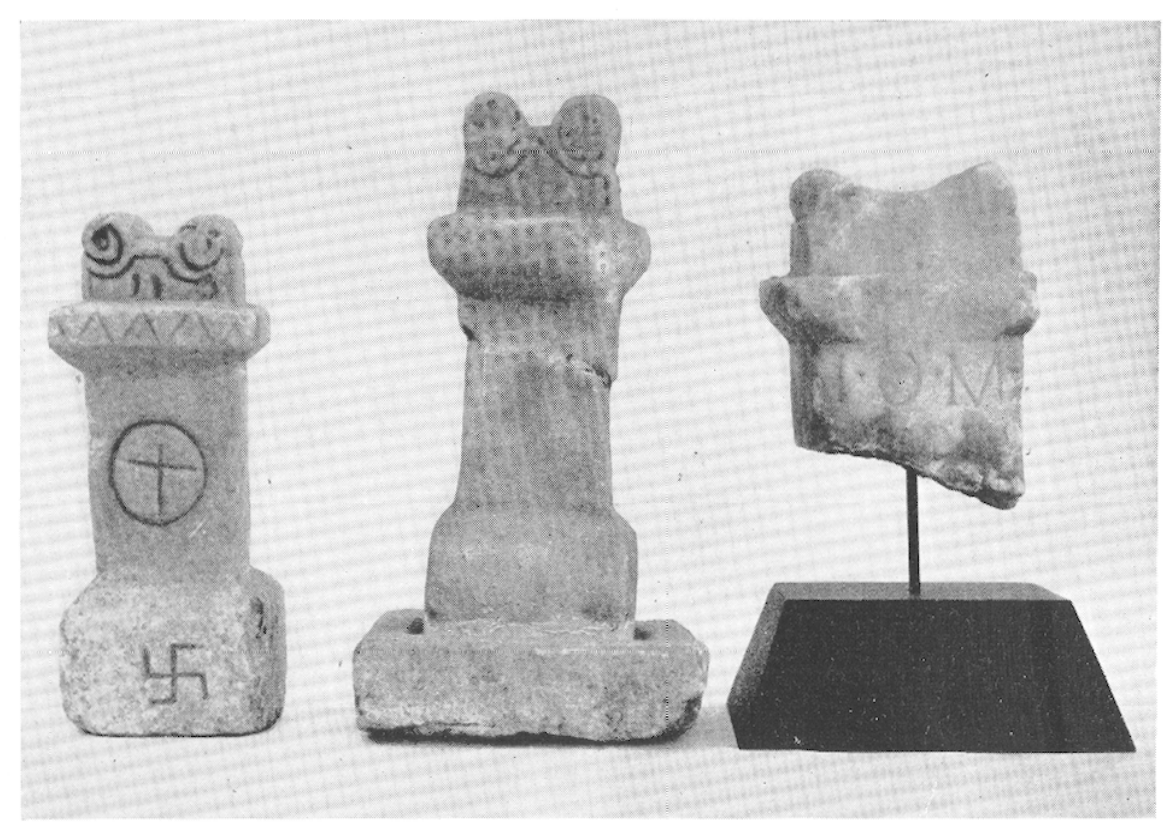

Fig. 18. - Petits autels du temple de la Villa de Montmaurin (Photo L. Barbé).

dédicace $I O M$ est, sur une découverte d'Angleterre (fig. 19), accostée de rouelles croisillonnées ${ }^{70}$ que nous retrouvons en Comminges sur un autel de la villa de Montmaurin (fig. 18), tout à côté d'une autre dédicace à $I O M$, sur l'autel du sommet du Montlas, sur l'arrière de la base de l'autel d'Arnesp, symétriquement à la svastika (fig. 17).

Les rouelles, sur la dédicace de la figure 19 , encadrent la svastika. Nous avons retrouvé 30 fois ce signe en Comminges ${ }^{71}$ consacrant bases ou socles d'autels votifs en marbre de St-Béat.

Les lieux de trouvaille des 5 socles où figure la svastika sont évocateurs : aux deux

p. 35 ; R. Lefort des Ylouses, La roue, la svastika et la spirale : symboles antiques du tonnerre et de la foudre, Gazette des Beaux Arls, 1955, juillet-août, pp. 8-9.

(70) R. Lefort des Yrousrs, op. cit., fig. 3. F, d'après le $\mathrm{n}^{\circ} 366$ du Lapidarium seplenlrionale de J.-C. Bruce.

(71) Nous remercions bien amicalement $M^{11}$ E. Eychenne, professeur d'Histoire au Lycée de SaintGaudens, qui a bien voulu libéralement nous communiquer son Inventaire des aulels votifs pyrénéens, annexe de son diplòme d'Études supérieures encore inédit. 14 autels étaient répertoriés dans sa Table générale des décors, portant la svastika. Nous nous sommes bornés à compléter cette liste. recueillis sur le Mont-Sacon l'on doit ajouter celui trouvé par M. Mothe sur le sommet du Montlas, un socle venant du lieu de culte de Montsérié avec 3 autels dédiés à Jupiter ${ }^{72}$, un autre enfin de la Croix de l'Oraison où il pouvait supporter des autels à Fagus ou à végétaux stylisés ${ }^{73}$.

Aussi révélateurs apparaissent les 25 autels portant svastika sur la base : - sur les 14 lieux de provenance connus ${ }^{74} 8$ ont fourni des dédicaces $I O M^{75}, 1$ Fago $D e o^{76}, 2$ ont

(72) Ch. L. Frossard, op. cil., p. 168 et 172.

(73) Baron d'Acios, Congrès Archéologique de France Agen-Toulouse 1874, p. 554 (la svastika est toujours improprement appelée par d'Agos "croix polencée ").

(74) 4 autels de provenance inconnue : 1 au Musée de Toulouse (J. SaCaze, op. cil., no 358 bis), 1 au Musée de Iuchon (J. Castex, op. cil., no 23) et 2 à rouelles ou rosaces probablement dédiés à Jupiter : Musće de Toulouse et Musée de Saint-Bertrand (Espérandieu, 863, 1 et 2).

(75) Montmaurin (fig. 18), Saint-Plancard (FouET, op. cit., fig. 10, p. 91), Arnesp (fig. 17), Ilheu (Gallia, XII, 1954, I, p. 220), Mont-Sacon (n ${ }^{\circ s} 13,44,47$ et peut-être 42), Bramevaque (J. SACAzF, op. cil., no 393) Montsérić ( 2 bases d'autels portant svastika sous un buste, ef. note 66), Saléchan (base d'autel à svastika, signalée par Mile Eychenne dans le mur de l'église où vient d'être tout récemment découvert un autel dédié à 1.O. M. inédit).

(76) Cf. ci-dessus, notes 58-59. 
attesté le culte d'un dieu dont l'on ne connaît que la dénomination indigène, Lexus ${ }^{77}$ et Erriapus $^{78}, 1$ a fourni de nombreuses trouvailles mal connucs mais où figure un autel à deux rosaces ${ }^{79}$, un dernier n'a pas révélé d'autre marbre cultuel ${ }^{80}$. Sur ces 25 autels, 9 sont actuellement muets ou ont perdu le dé ${ }^{81}$, mais 16 conservent sur leur dé :

a) les plus nombreux (6), un végétal stylisé ${ }^{82}$

b) presque en même nombre (5), une rouelle ou rosace r3 $^{83}$

c) 4, une figuration de divinilé masculine ${ }^{84}$

d) un seul, une inscription à Erriapus ${ }^{85}$.

Indifléremment tournée vers la droite ou la gauche, la svastika paraîtrait ainsi réservée, dans les Pyrénées centrales, comme signe de consécration à la base d'ex-voto offerts à une toute puissante déité céleste à qui le dédicant plus romanisé d'un autel de Lescure, près de Saint-Lizier (Ariège) semble aussi s'adresser de manière plus explicite mais non moins suggestive: I O M AVGTORI BON ARVM TEMPESTATIVM : A Jupiler très bon, très grand, auleur des bonnes saisons ${ }^{86}$. Ces svastikas, parfois remplacées par de petites croix

(77) J. SACAZE, op. cil., nos 376-377.

(78) M. Labrousse, Nouveaux autels votifs de Saint-Béat, Revue de Comminges, LXIV, 1951, p. 76.

(79) J. Castex, op. cil., nos 65-66: découvertes Bourdette dans les ruines de l'église Sainte-Christine à Montauban-de-Luchon actuellement disparues.

(80) Petit autel seulement signalé par B. SAPÈnE, Chronique commingeoise, Revue de Comminges, LXX, 1957 , p. 38.

(81) Autels de Garraux, Saint-Plancard, Lez, Saléchan, Saint-Béat ( 2 bases : cf. note 72 ), Aveux (semble-t-il disparu ? Collection d'Agos, no 4 des anépigraphes), Musée de Luchon (J. CAstex, op. cit., nos 23 et 66 ).

(82) Ilheu, Arnesp, Croix de l'Oraison à Tibiran, Mont-Sacon, Sost (2).

(83) Montmaurin, Mont-Sacon (2) et EspérandiEC, no 863,1 et 2 .

(84) Bramevaque, Montsérié (Espŕr. 851 et 853), Garin (J. SACAZE, 358 bis).

(85) M. Labrousse, op. cil., p. 76.

(86) Il est remarquable que le Moyen Age paraisse avoir réservé la figuration de la rouelle et de la svastika aux représentations de la croix : E. MaIf, La fin du paganisme en Gaule, Paris, 1850, p. 309 ; M. Bourrin, Svastika et sauvastika, Annales de la Société Scientifique et Lilléraire de Cannes, XIV, 1952-53, p. 26. plus simples à branches égales, semblent avoir été gravées en guise de signe talismanique par la main même des dédicants. Peut-être ontelles eu le sens bénéfique de la "Croix des 4 vents ", mais elles ne paraissent en rien avoir figuré la foudre ${ }^{87}$.

Les autels portant figurations humaines ne nous sont malheureusement parvenus qu'incomplets ou érodés et l'on ne peut savoir si quelque svastika figurait sur leur base. Un couronnement conserve, semble-t-il, une représentation végétale $\left(\mathbf{n}^{0} 6\right)$. Un autre autel, découvert à $\Lambda$ nla, avec dédicace à Jupiter, présente l'association d'une figuration humaine et de pousses végétales ${ }^{88}$.

A Hèches et à Arlos deux bustes étaient

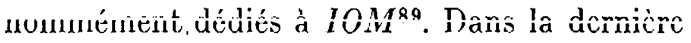
de ces localités un autre autel, déjà cité, porte un personnage tenant une pierre et un bâton, comme peut-être l'autel cassé no 40 . Ces attributs ne seraient-ils pas à rapprocher des insignes des prêtres du plus ancien sanctuaire romain de Jupiter à savoir un silex et un bâton ?90. Un certain nombre de personnages nus sculptés sur les autels pyrénéens s'appuient manifestement sur un bâton. L'un d'eux, sur un autel de Bramevaque trouvé avec un autre autel dédié à Jupiter à la base du Mont-Sacon, semble tenir de l'autre main un serpent ${ }^{91}$. Une svastika en décore la base cependant qu'un large vase, sur le couronnement, pourrait évoquer l'abondance dispensée par le dieu ${ }^{92}$.

Sur bon nombre de représentations romaines, notamment sur des deniers, Jupiter est représenté jeune, imberbe, l'air énergique, les chevcux aux vents, tenant parfois un long sceptre ou bâton, et il semblerait bien que ce soit ce type même de figuration qui soit le plus répandu sur les petits autels commingeois.

(87) R. LeFort des Yloushs, op. cit.

(88) J. SACAZE, op. cil., no 389, 2.

(89) Ibid., nos 454 et 287.

(90) V. Basanoff, Les dieux des Romains, Paris, 1942 , p. 46.

(91) Même personnage à Gaud : J. SAca7e, op. cit., p. 352. Sur le serpent, attribut de Jupiter ou du dieu à la roue : R. Lefort des Ylousrs, op. cit., p. 8.

(92) Ce vase d'abondance, très rare sur les autels pyrénéens, ne serait pas sans évoquer les insuffisances pacagères de Bramevaque dont le nom même paraît traduire la détresse de bovidés mal nourris. 
Tous les indices semblent donc concorder pour montrer que la divinité vénérée sur le Mont-Sacon est bien Jupiter, dieu souverain du ciel, du temps et de la nature. Si le culte dont nous avons observé les manifestations se place sans aucun doute en pleine époque romaine, ainsi qu'en lémoignent non seulement la monnaie, mais aussi les marbres taillés, les représentations anthropomorphes el la dédicace au Jupiter Capitolin, il n'en reste pas moins que ces rites romanisés recouvrent. un culte primitif de nature plus ancienne. Les pousses végétales, en particulier, permettent d'identifier la persistance d'un stade antérieur, au niveau duquel le dieu ne se distinguait pas de l'arbre qui lui était consacré. Le Fagus Deus de la Croix de l'Oraison, comme le dieu Sex Arbores de Castelbiague, correspondent, en eflet, à un aspect du culte que l'on retrouve en partie au Mont-Sacon et aussi au Fagulal de Rome, où, comme on le sait ${ }^{93}$, se dressait en plein air, dans une enceinte, un hêtre, qui était considéré comme l'émanation sacrée de Jupiter (sacellum Jovis in quo fuil fagus arbor quae Jovis sacra habebatur). A celle ctape de la dialectique religieuse les offrandes devaient consister en de simples rameaux de verdure ou en de jeunes plants, le temple se réduisait à une portion délimitée de la surface du sol et le dieu, qui n'avait ni nom ni visage, n'était rien d'autre qu'un arbre, un arbre-dieu, hêtre-dieu ou groupe divin de six arbres.

C'esl ce slade primitif, c'est-à-dire premicr, que l'on reconnait non seulement dans la représentation des végétaux stylisés mais aussi dans celle des rouelles el des svastikas - qui sont des figures géométriques simples, à valeur magique élémentaire - tandis que les personnages, si maladroite que soit leur expression, tout comme la dédicace à $I O M$, signifient que sous l'influence romaine les riles jusqu'alors implicites commençaient à accéder à un stade plus évolué. Les vestiges recueillis sur le MontSacon témoignent donc d'un culte à la fois indigène et romanisé, célébré par une population rustique qui, tout en conservant ses anciennes traditions, avait déjà pleinement adopté les

(93) Cf. note 66. modes d'expression d'une civilisation supérieure.

$$
\text { ** }
$$

Première montagne dominant au bord de la plaine le chef-lieu de cité des Convènes, massif lutélaire des vallées d'Arize et de Barousse dont il règle le temps et qu'il alimente de ses eaux, de sa forêt, de ses pâlurages, le Mont-Sacon semblait bien inviter les hommes qui l'enlouraient à déposer sur sa cime même des offrandes destincées au dieu du ciel.

Maître des phénomènes météorologiques, du

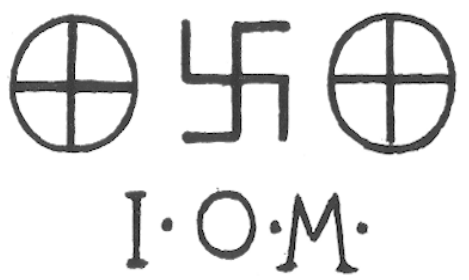

Fig. 19. - Fxemple de svastika accompagnéc de rouelles et initiales de Jupiter (d'après R. Leforl des Ylouses, op. cil.).

beau temps, de la chaleur, de la pluie et des vents, cet "auteur des bonnes saisons ", libéral distributeur des biens de la terre, a été sans doute considéré comme "l'incarnation de la force mystérieuse qui anime la nature, qui fait couler les eaux et grandir les arbres "94, tout comme le Jupiter romain primitif ${ }^{95} \mathrm{ou}$ l'ancien Zeus de la Grèce, que l'on adorait également sur les sommets ${ }^{96}$.

L'emplacement, où devait se dresser, sur la cime, le simple autel de pierres amoncelées ${ }^{97}$, restera d'ailleurs un point de repère où se joignent encore les limites de trois territoires communaux ${ }^{98}$. Mais, en plus des vestiges

(94) R. Pinnoun, Les Gaulois, p. 73.

(95) Maitre de la pluie et nourricier par excellence : P. Pínп Ri\%ex, art. Jupiler du Dict. des Anliq.

(96) Zeus Fpacrios (montagnard), d'après Hésychius : cf. Parly-Wissowa, Realencylopädie, s.v. Jupiter, colonne 1127 .

(97) Sans doute comparable à l'autel de Zeus au sommet du Mont Lycée en Arcadie et à l'autel fig. 407 de l'article Ara du Isic:. des Anliq.

(98) Le sommet du Donon restera la limite de 3 peuples : E. Linckexhelo, Le sanctuaire du Donon, Cahiers d'archéologie el d'Hisloire d'Alsace, 1947. 
archéologiques et lopographiques le nom même de la crête du Mont-Sacon devait conserver jusqu'à nos jours le souvenir des autels votifs déposés par les populations galloromaines. Lors du premier sondage, alors que le mauvais temps menaçait de toute part, un berger de Sacoué, qui se trouvait dans les parages, nous indiqua que l'abri le plus proche était la cabane de Marmés, nom que nous avons retrouvé par la suite sur les cadastres de Bramevaque, d'Ourde et de Sacoué. Les trouvailles ont été faites, en effet, sur la Serre de las Marmés, entre Tourroc et la Tourelle. de Marmés, en haut du pâturage de Marmés où se dresse la cabane secourable. Bien que le sens de ces lieux-dits ne soit plus saisi par les habitants du pays, il ne fait pas de doute que le toponyme Marmés - avec l'accent tonique sur la première syllabe - soit le continuateur occitan ou gascon du latin marmor ${ }^{99}$. Le mot est attesté, non seulement en ancien provençal ${ }^{100}$ mais aussi dans quelques dialectes actuels du Midi de la France (Provence, Toulousain, Lomagne, Béarn $)^{101}$ : il signific morceaux de marbre, ou plus exactement pierres de marbre, puisque l'expression complète, employée le plus souvent et qui, d'ailleurs, explique que le mot soit maintenant féminin (Serre de las Marmés) est, au singulier, peyromarme ${ }^{102}$. Non loin du Mont-Sacon, entre le Pic de Monllas et le Pic de Couret Médan, le col de Peyros-Marmés, où l'on a trouvé de grands autels votifs, perpétue dans la toponymic une appellation ancienne $e^{103}$ dont le sens a été confirmé, ici comme là, par l'exploration archéologique.

L'analyse toponymique décèle donc, dans le nom de pâturage culminant du Mont-Sacon, la présence prolongée de ces marbres insoliles, à demi enfouis dans les herbes, sur lesquels les bergers ont cru reconnaître des fleurs ${ }^{104}$.

(99) Sur le passage de marmor à " marme", cf. J. AN(iLADE, Grammaire de l'ancien provençal, Paris, 1921, p. 200.

(100) E. LÉvy, Petil Dictionnaire Provençal-Fraņ̧ais, Heidelberg 1909, s.v. marme.

(101) J. Ronjat, Grammaire IIislorique des parlers provençaux modernes, Montpellier, 1932, \$430.

(102) J. Ronjat, op. cit., ibidem.

(103) Dans le dialecte actuel marbre se dit marbré.

(104) Il est intéressant de noter que dans le Tarn
La mention précise de roses, dans les récits légendaires qui sonl parvenus jusqu'à nous, pourrait être interprétée également comme un souvenir du cultc gallo-romain, ainsi que l'on peut en juger par les réflexions que suggèrent à Adolf Bach, dans son manuel classique de loponymie allemande ${ }^{105}$, les noms de lieu Rosengarlen que l'on rencontre fréquemment dans les Alpes : "Il est généralement admis que le toponyme très répandu Rosengarten est traduit du latin. Les Romains fêtaient au mois de mai les Rosalia, la fête des roses; c'était une cérémonie au cours de laquelle on distribuait des roses que l'on déposait sur les tombes... Le cimetière devenait ainsi un pratum rosarum, une roseraie. On pense que cette coutume, ainsi que le terme qui la désignait, a été transmise aux Germains par les Romains. Le nom de Rosengarten désignait alors les cimetières et les endroits hantés par des êtres surnaturels. Aujourd'hui encore, en Suisse et dans d'autres pays des Alpes, les cimetières s'appellent Rosengärten "106. Ces roseraies, aussi bien dans les noms de lieu que dans les légendes, sont placées sur des sommets ou à des cols où ne peuvent pousser manifestement ni des roses de jardin, ni même des roses de montagne (rhododendrons). C'est, ainsi que dans les Dolomites du Tyrol Méridional s'est maintenue jusqu'à nos jours la légende de la hoseraie de Laurin, le Roi des Nains. Ce Rosengarlen, qui joue un grand ròle, dès le $\mathrm{xIn}^{\mathrm{e}}$ siècle, dans l'épopée courtoise de Laurin, en langue allemande (Ze Tirol in dem lanne dà hàl er erzogen zarlen einen rosengarten.... Au Tyrol, dans un bois de sapins, il a fait pousser amoureusement des roses...), vit encore dans les contes populaires du Val de Fassa, au pied de la Marmolada. La version en dialecte ladin, recueillie par K. F. Wolf1 ${ }^{107}$ mentionne un Roi de Nyès (localité légendaire

le menhir de la Bayourthe (commune du Bez), qui est orné d'une vague gravure pédiforme, s'appelle Peyro Flourido. I.e même terme de peyro flourido désigne, en Lozère, dans le langage courant, les ammonites (noté dans la commune de Cocurès).

(105) Deutsche Namenkunde, II, Die deulschen Orlsnamen, Heidelberg, 1954.

(106) Ibidem, $\$ 449$.

(107) König Laurin und sein Rosengarten, BozenBolsano, 1947, p. 123. 
située en haute montagne) qui, comme la reine Marguerite, plantait des roses sur les sommets. Nous citons une partie de ce texte dont la langue savoureuse rend un son familier aux oreilles gasconnes et occitanes : " $T e i$ prumes tempes, lan ke se slaséa ben, el Réy de Nyès lèa de bie ortch kon tsondres lie le fajéa de gren fyores roch. E sta mont se la vedéa rossa da da lendch.... Dans les premiers temps, alors que tout le monde vivait bien, le Roi de Nyès avait de beaux jardins avec des rosiers qui portaient de grandes fleurs rouges. Et cette montagne, on la voyait rougeoyer de loin... " K. H. Wolff signale, en plus des Monts $d u$ Rosengarten près de Bozen ou des autres Rosengärlen de la région (près de Ritten, Igls, Lienz), quelques toponymes des Alpes où apparaissent aussi des roses et il est intéressant de remarquer que ces noms de lieux sont situés souvent à des cols que franchissent de vicux chemins : par exemple, le Rosenjoch près d'Innsbruck ou le Plan des Roses (altitude 2415 mètres) dans le Valais suisse. Comme il ne s'agit pas ici de cimetières, on ne peut s'empêcher de penser à des lieux de culte situés en bordure de voies anciennes, à l'endroit même où il convenait d'invoquer les dieux.

Dans le cas du Mont-Sacon, le Jardin de la Reine Marguerite pourrait être le souvenir d'un enclos cultuel où les fidèles déposaient des branches et des roses qu'ils consacraient au dieu de la montagne au cours d'une cérémonie printanière. Et ce seraient ces mêmes roses, dont le souvenir avait survécu dans les traditions orales, que les bergers ont cru reconnaître dans les rouelles à quatre branches des autels votifs.

Par-delà les noms de lieu et les légendes d'origine gallo-romainc, il scmble, enfin, que l'analyse toponymique puisse remonter dans le lemps à une époque plus ancienne encore, où les montagnards des Pyrénées ne connais- saient ni la taille des pierres, ni les inscriptions votives, ni même le nom de ce dieu de la montagne auquel ils n'offraient que des rameaux de feuillage qui n'ont laissé aucune trace sur le sommet. Car la trace durable de ce culte primitif, antérieur chronologiquement et dialectiquement à la codification des Romains et des théologiens, se retrouve, semble-t-il, dans le nom même du Mont-Sacon. Si Sacco que l'on rencontre dans des anthroponymes ${ }^{108}$ est bien, comme le propose le linguiste K. II. Schmidt ${ }^{109}$, le même mot que sacro, adjectif qui correspond au latin sacer et qui signifie "consacré à un dieu " (einem Gotte geweiht), il se pourrait que les Convènes de Lugdunum, dès le $\mathrm{I}^{\text {@r }}$ siècle avant J.-C., aient désigné de ce nom dans leur langue une montagne sainte qu'adoraient sans doute avant eux leurs prédécesseurs.

Ainsi serait parvenu jusqu'à nous le nom prestigieux d'une cime sacrée, que la légende a fleurie de roses de marbre, encloses dans un jardin royal, et à qui la recherche, tant archéologique que toponymique, restitue enfin, ses vrais titres de noblesse.

Georges Fouet et André Soutou.

(108) Holder, Alt- celtischer Sprachschalz, Ieipzig 1890 , s.v. Sacco, Saccomainus.

(109) Karl Horst Schmint, Die Komposition in gallischen Personennamen, Zeitschrift für celtische Philologie, 26, 1957, p. 33-301, s.v. Sacco. I'auteur considère que le - $c c$ - de Sacco provient de l'assimilation du groupe consonantique - cr- de sacro. Dans le cas qui nous occupe, le redoublement du $c$ intervocalique explique le maintien de la sourde dans Sacon. Quant au suffixe - on, qui porte l'accent, il peut être, soit une désinence gauloise originelle, soit l'augmentatif latin - one qui a laissé de si nombreuses traces dans la toponymie (ef. $\Lambda$. Soutou, L'augmentatif latin - one dans la toponymie languedocienne, Via Domilia, 1956, p. 8-13). Mont-Sacon signifierait donc la grande monlagne sacrée. 